\title{
Enabling low-carbon hydrogen supply chains through use of biomass and carbon capture and storage: A Swiss case study
}

Journal Article

Author(s):

Gabrielli, Paolo; Charbonnier, Flora; Guidolin, Annalisa; Mazzotti, Marco

Publication date:

2020-10

Permanent link:

https://doi.org/10.3929/ethz-b-000425987

Rights / license:

Creative Commons Attribution 4.0 International

Originally published in:

Applied Energy 275, https://doi.org/10.1016/j.apenergy.2020.115245 


\title{
Enabling low-carbon hydrogen supply chains through use of biomass and carbon capture and storage: A Swiss case study
}

\author{
Paolo Gabrielli, Flora Charbonnier ${ }^{1}$, Annalisa Guidolin, Marco Mazzotti* \\ Institute of Energy and Process Engineering, ETH Zurich, 8092 Zurich, Switzerland
}

\section{H I G H L I G H T S}

- Rationale behind multi-objective design of low-carbon hydrogen supply chains.

- Competition of several solutions for low-carbon hydrogen production.

- Competition and interplay between hydrogen, biomass and $\mathrm{CO}_{2}$ networks.

- Impact of $\mathrm{CO}_{2}$ value chain features on optimal design of hydrogen supply chains.

- Impact of biomass availability on optimal design of hydrogen supply chains.

\section{A R T I C L E I N F O}

\section{Keywords:}

Hydrogen supply chains

Carbon capture and storage

Biomass

Networks

Optimization

Energy transition
G R A P H I C A L A B S T R A C T

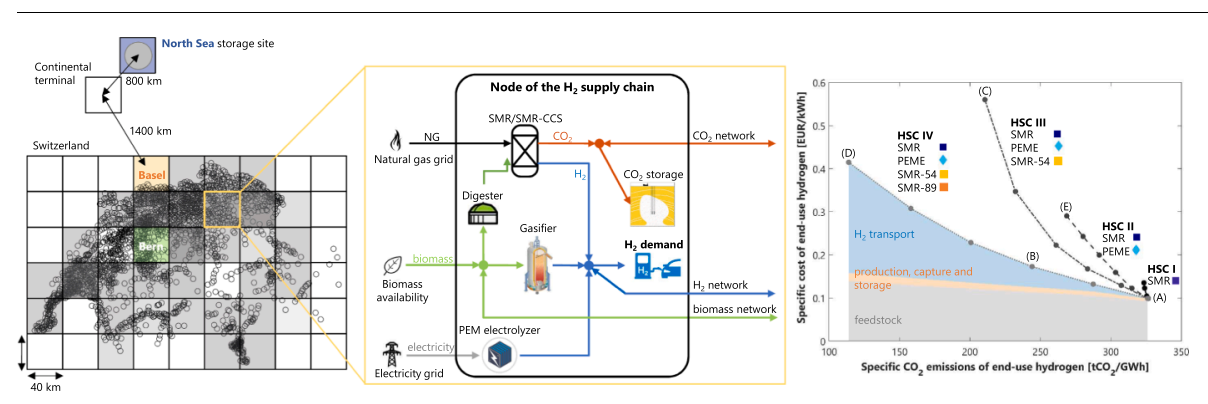

\begin{abstract}
A B S T R A C T
This study investigates the optimal design of low-carbon hydrogen supply chains on a national scale. We consider hydrogen production based on several feedstocks and energy sources, namely water with electricity, natural gas and biomass. When using natural gas, we couple hydrogen production with carbon capture and storage. The design of the hydrogen, biomass and carbon dioxide $\left(\mathrm{CO}_{2}\right)$ infrastructure is performed by solving an optimization problem that determines the optimal selection, size and location of the hydrogen production technologies, and the optimal structure of the hydrogen, biomass and $\mathrm{CO}_{2}$ networks. First, we investigate the rationale behind the optimal design of low-carbon hydrogen supply chains by referring to an idealized system configuration and by performing a parametric analysis of the most relevant design parameters of the supply chains, such as biomass availability. This allows drawing general conclusions, independent of any specific geographic features, about the minimum-cost and minimum-emissions system designs and network structures. Moreover, we analyze the Swiss case study to derive specific guidelines concerning the design of hydrogen supply chains deploying carbon capture and storage. We assess the impact of relevant design parameters, such as location of $\mathrm{CO}_{2}$ storage facilities, techno-economic features of $\mathrm{CO}_{2}$ capture technologies, and network losses, on the optimal supply chain design and on the competition between the hydrogen and $\mathrm{CO}_{2}$ networks. Findings highlight the fundamental role of biomass (when available) and of carbon capture and storage for decarbonizing hydrogen supply chains while transitioning to a wider deployment of renewable energy sources.
\end{abstract}

Abbreviations: B, Dry biomass; b, Wet biomass; BECCS, Bio-Energy with Carbon Capture and Storage; CCS, Carbon Capture and Storage; COP, Conference of Parties;

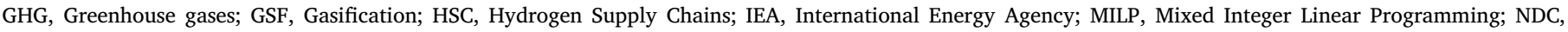

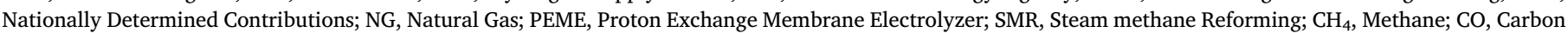
monoxide; $\mathrm{CO}_{2}$, Carbon dioxide; $\mathrm{H}_{2}$, Hydrogen; $\mathrm{O}_{2}$, Oxygen

* Corresponding author.

E-mail address: marco.mazzotti@ipe.mavt.ethz.ch (M. Mazzotti).

${ }^{1}$ Current affiliation: Department of Engineering Science, University of Oxford, Oxford, United Kingdom 


\section{Introduction}

The evidence that the anthropogenic alteration of the earth carbon balance is leading to climate change, together with the confirmation of its consequences, has clearly indicated the necessity of finding new routes for energy provision, where no-carbon emission is achieved around 2050 and global warming is kept below $1.5^{\circ} \mathrm{C}$ [1]. However, the main message of the last conference of the parties (COP) of the United Nations Convention on Climate Change was that "unless Nationally Determined Contributions (NDC) ambitions are increased before 2030, exceeding the $1.5{ }^{\circ} \mathrm{C}$ goal is unavoidable. Now more than ever, unprecedented and urgent action is required by all nations" [2]. According to the latest report of the International Energy Agency, hydrogen offers ways to decarbonize a range of sectors, including the transport sector, where it is proving difficult to meaningfully reduce emissions [3]. On the one hand, the report points out that hydrogen is enjoying an unprecedented momentum around the world and could finally fulfill its longstanding potential as clean energy solution. On the other hand, it highlights the challenges that a clean and widespread use of hydrogen would face, mostly related to the development of hydrogen infrastructure. This calls for a planning activity that accounts for the economic and the environmental impacts of hydrogen supply chains, as well as for the interplay between other supply chains connected to hydrogen generation and consumption [4,3]. This holds in the specific case of the mobility sector, where the main obstacle for the deployment of hydrogen $\left(\mathrm{H}_{2}\right)$-based vehicles is the lack of hydrogen infrastructure $[5,6]$.

As a consequence, a number of works have developed and implemented decision-support tools for the design and operation of hydrogen supply chains (HSC), with HSC being defined as a network of hydrogen production and consumption facilities that can be interconnected by means of several network options $[7,8]$. Such works have addressed the design of HSC from a national to a regional scale, with Almansoori and Shah leading the way $[9,10]$ and Agnolucci and McDowall following [11]. Some studies include the selection of production technologies (such as steam methane reforming (SMR) based on natural gas, biomass gasification or anaerobic digestion, water electrolysis based on electricity) and of network options (such as truck, train, pipeline, ship) $[12,13]$, though most of the studies focus on the latter [14-16]. Concerning hydrogen production, recent evidence suggests that SMR based on natural gas or biomass, coupled with carbon capture and storage (CCS), is currently the most economically and environmentally attractive option, while waiting for a future full deployment of renewable energy sources to power water electrolysis [17-19]. Concerning hydrogen transport, a few studies have compared different distribution networks and determined the optimal alternative for specific supply chains [20-22]. Multi-objective optimization frameworks have been investigated $[23,24]$ and used to assess the environmental and economic performance $[25,26]$, the risk aspects [27-29], and the life cycle [30-32] of the entire supply chains. Some optimization models have also considered the uncertainty associated to hydrogen demand by using stochastic programming [33-35].

However, a general analysis based on the intrinsic features of different types of network for hydrogen transport is missing [36,37]. Furthermore, while some studies highlighted the potential of biomass for reducing costs and emissions of the HSC [38,39], the coupling of hydrogen, biomass and carbon dioxide $\left(\mathrm{CO}_{2}\right)$ networks have seldom been investigated, though it is crucial when coupling fossil-based hydrogen production with CCS $[40,41]$. To fill these gaps, we model, optimize and assess hydrogen supply chains in which hydrogen production is based on several energy sources, namely electricity, natural gas and biomass, and can be coupled with CCS to offset the $\mathrm{CO}_{2}$ emissions resulting from the reforming of natural gas. Furthermore, several network options, such as train, truck and pipeline, are available for transporting hydrogen, $\mathrm{CO}_{2}$ and biomass. An optimization problem is solved to determine the optimal selection, size and location of the hydrogen production technologies, as well as the optimal structure of the hydrogen, biomass and $\mathrm{CO}_{2}$ networks. The optimization algorithm is formulated as a mixed integer linear program (MILP), which minimizes the total annual cost and the total $\mathrm{CO}_{2}$ emissions of the supply chain while satisfying the hydrogen demand of a pre-defined set of end users. The optimal solution requires the knowledge of the price and carbon intensity of the energy sources, the hydrogen demand, and the parameters defining cost and performance of the underlying production and network facilities.

The goal of the study is to explain the rationale behind the optimal design of low-carbon hydrogen supply chains under different system configurations. Accordingly, we investigate the competition of (i) hydrogen production processes characterized by different economic and environmental impacts, (ii) $\mathrm{CO}_{2}$ capture technologies characterized by different values of capture rate and cost, (iii) transport options characterized by different economic and environmental impacts, (iv) $\mathrm{H}_{2}$ and biomass transport for different values of biomass availability and network characteristics, (v) $\mathrm{H}_{2}$ and $\mathrm{CO}_{2}$ transport for different locations of the $\mathrm{CO}_{2}$ storage and of the network characteristics. First, we investigate general aspects of the design of hydrogen supply chains by referring to an idealized system configuration characterized by a fictitious and symmetrical distribution of the hydrogen demand. This results in an idealized and symmetrical network structure, with a clear distinction between urban and rural needs. Whereas we do not perform a fullblown sensitivity analysis of the optimization model to address the uncertainty of the input data, we believe that this approach allows identifying the most relevant parameters in terms of system design and drawing general considerations independently of any specific application with its specific geographical patterns. Furthermore, such a configuration is also used to study the optimal design of hydrogen supply chains using biomass as energy source, as well as the interplay between $\mathrm{H}_{2}$ and biomass networks. Then, due to the specificity of the available $\mathrm{CO}_{2}$ storage facilities, the optimal design of hydrogen supply chains deploying CCS is investigated by considering a realistic system configuration representing a Swiss case study. The interplay between hydrogen and $\mathrm{CO}_{2}$ networks is investigated, and realistic guidelines are derived for the design of hydrogen supply chains coupled with carbon capture and storage.

Finally, we note that combining the use of biomass as energy source with CCS chains would allow obtaining hydrogen with net-negative $\mathrm{CO}_{2}$ emissions [42-44]. Such a route is referred to as BECCS (bio-energy with carbon capture and storage) and will most likely be key in the second half of the century to compensate for an overshoot in global temperatures and to cope with unavoidable positive emissions, for example, from aviation and shipping and from agriculture $[1,43]$. However, this goes beyond the scope of this paper, where biomass and CCS are considered separately.

The paper is structured as follows. Section 2 describes the system configurations considered to perform the analysis and Section 3 formulates the multi-objective optimization problem used to determine the optimal system design. Section 4 introduces general aspects of the minimum-cost design of HSC. Section 5 and Section 6 determine how to reduce costs and emissions of HSC by deploying biomass and CCS, respectively. Section 7 synthesizes general design guidelines for minimum-emissions HSC. Finally, major findings are summarized and conclusions are drawn in Section 8.

\section{System description}

The hydrogen supply chains (HSC) considered in this work have the primary objective of supplying hydrogen for mobility purposes to fulfill the energy demands of given end users. Two system configurations are defined, which are characterized by two different distributions of $\mathrm{H}_{2}$ demand.

- Idealized system configuration. First, we consider an idealized 
distribution of the $\mathrm{H}_{2}$ demand, which is illustrated by the gray tones of the cells in Fig. 1-a. Here, the urban $\mathrm{H}_{2}$ demand is assumed to account for $95 \%$ of the total demand and to be equally distributed among 4 end users, which are disposed symmetrically (dark gray cells). In the same way, the rural $\mathrm{H}_{2}$ demand is assumed to account for $5 \%$ of the total demand and to be equally distributed among 32 end users, which are also disposed symmetrically (light gray cells). This translates into a symmetrical structure of the supply chain, with a clear distinction between rural and urban needs. Such an idealized and symmetric demand distribution allows deriving general design guidelines independently of any specific geographic bias. This configuration is adopted in Section 4 to draw general conclusions on the minimum-cost design of HSC, and in Section 5 to focus on the role of biomass within low-carbon HSC.

- Swiss case study. Next, we consider a realistic distribution of the $\mathrm{H}_{2}$ demand representing a Swiss case study (see Fig. 1-b). This is defined by collecting data on population and motorization rate for all municipalities in Switzerland $[45,46]$, which are aggregated based on their geographic location according to a given spatial resolution. For cells whose $\mathrm{H}_{2}$ demand is too small to justify hydrogen production, the $\mathrm{H}_{2}$ demand is transferred to the adjacent cell associated to the highest demand. An additional cell is added outside Switzerland to represent a potentially available $\mathrm{CO}_{2}$ storage site in the North Sea (e.g. Northern Lights project off the Norwegian shore gray circle in Fig. 1-b). $\mathrm{CO}_{2}$ can be transported from Switzerland to such a storage site via a continental terminal (e.g. located in the port of Rotterdam in The Netherlands, or in North Germany). This configuration is adopted in Section 6 to focus on the role of carbon capture and storage (CCS) within low-carbon HSC.

In both cases, a uniform spatial discretization is adopted through square cells of a specific size ( $40 \mathrm{~km}$ by $40 \mathrm{~km}$ in the cases studied here), with each cell representing a node of the overall HSC. Each cell is connected to all neighboring cells (see example in Fig. 1-a). The parameters defining the two system configurations (e.g. adopted spatial resolution) are reported and discussed in Section S3 of the Supporting Information.

Hydrogen can be produced starting from different feedstocks and energy sources, namely water with electricity, natural gas (NG) and biomass. $\mathrm{CO}_{2}$ can be captured by NG-based production plants. The hydrogen production facilities can be connected to the hydrogen end users, to the $\mathrm{CO}_{2}$ storage facility and to the biomass source through a)

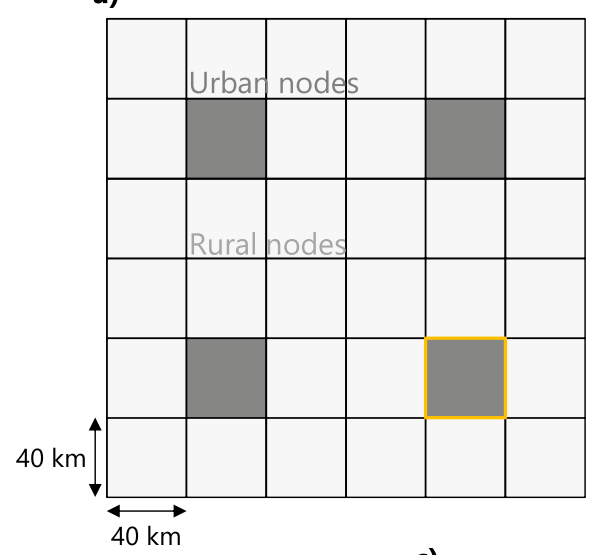

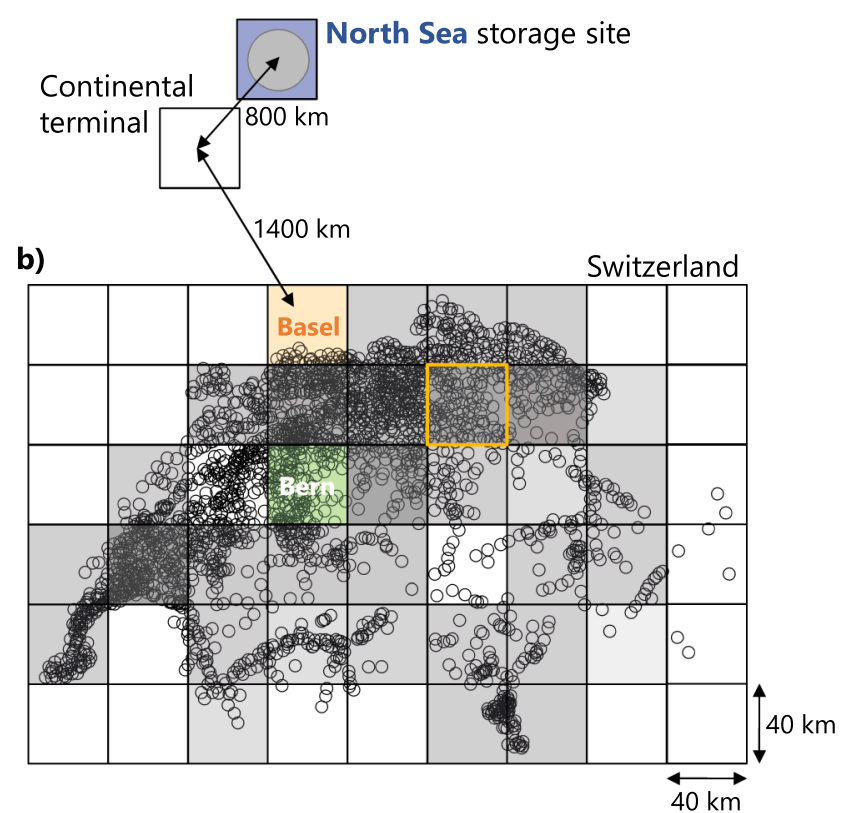

c)

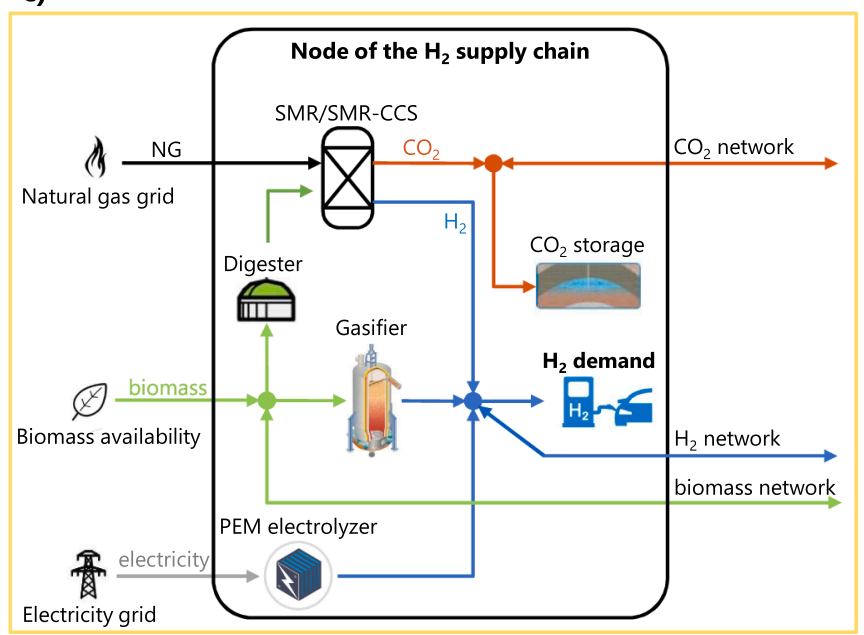

Fig. 1. (a) Idealized system configuration characterized by urban and rural cells. (b) Realistic system configuration representing Switzerland, with possibility of storing $\mathrm{CO}_{2}$ in the North Sea (gray circle). Hydrogen demand described by the gray tones of the cells. (c) Representation of a node of the HSC including the considered conversion and storage technologies, as well as the considered networks. 
several network technologies. Fig. 1-c illustrates the portfolio of available production technologies within each node of the HSC. This consists of:

- Proton exchange membrane (PEM) electrolyzers, which use electricity to produce $\mathrm{H}_{2}$ and $\mathrm{O}_{2}$ at high-pressure through the splitting of deionized water. The PEM electrolyzer technology is modeled based on the work of Gabrielli et al. [47]. Here, $\mathrm{O}_{2}$ is assumed to be vented to the environment and it is not considered in the analysis.

- Steam methane reforming (SMR) processes, which produce hydrogen starting from a feed of either natural gas or biogas. Here, biogas is produced through the anaerobic digestion of waste biomass (e.g. manure), which is hereafter referred to as wet biomass. The SMR processes are modeled based on the work of Antonini et al. [48,49]. First, a reforming reaction at high temperature converts natural gas into syngas, i.e. a mixture of $\mathrm{H}_{2}, \mathrm{CO}, \mathrm{CO}_{2}$ and some residual of $\mathrm{CH}_{4}$. Then, the syngas is processed in a water gas shift reactor to convert $\mathrm{CO}$ and increase the content of $\mathrm{H}_{2}$. Finally, the gas is sent to a separation unit (pressure swing adsorption unit) that produces highpurity hydrogen on the one side and a tail gas on the other side. Such a tail gas is recirculated to the reformer as a fuel to sustain the reaction. The exhaust gases resulting from the fuel combustion are vented into the atmosphere, which results in direct $\mathrm{CO}_{2}$ emissions (contrary to the electrolyzer).

A $\mathrm{CO}_{2}$ capture unit can be installed to reduce such $\mathrm{CO}_{2}$ emissions. Following the latest IEAGHG report [50], we consider the installation of $\mathrm{CO}_{2}$ capture units at two different locations of the process, namely (a) at the exit of the water gas shift reactor, (b) after the reformer fuel combustion. Case (a) consists of a pre-combustion $\mathrm{CO}_{2}$ capture unit with a $90 \%$ capture rate, which captures the $\mathrm{CO}_{2}$ present in the syngas only, while it does not capture the $\mathrm{CO}_{2}$ resulting from the tail gas combustion. This results in a smaller capture unit (smaller flow rate of treated gas), hence lower costs, and in an overall capture rate of $54 \%$. We refer to this configuration as SMR54. Case (b) consists of a post-combustion $\mathrm{CO}_{2}$ capture unit with a $90 \%$ capture rate, which captures the $\mathrm{CO}_{2}$ present in process exhaust gases. This results in a bigger capture unit (bigger flow rate of treated gas), hence higher costs, and in an overall capture rate of $89 \%$. We refer to this configuration as SMR-89. In this work, $\mathrm{CO}_{2}$ capture processes are applied to NG-based SMR only. Hereafter, SMR running on NG is simply denoted as SMR, whereas the process involving the anaerobic digestion of wet biomass, the upgrading of the resulting biogas and the reforming of natural gas is denoted as bSMR.

- Gasification processes, which produce hydrogen starting from a feed of wood biomass, which is hereafter referred to as dry biomass. The gasification process is modeled based on references [51,52]. First, syngas is produced, which is then treated to produce $\mathrm{H}_{2}$ through several steps. These include reformers, high-temperature and lowtemperature water gas shift reactors, cyclones and tar reformers to remove the solid particles in the mixture. After such steps, the gas is sent to a separation unit (pressure swing adsorption unit) that produces high-purity hydrogen on the one side and a tail gas on the other side. Such a tail gas is partially recirculated to the reformer as a fuel to sustain the reaction. The exhaust gases resulting from the fuel combustion are vented into the atmosphere, which results in direct $\mathrm{CO}_{2}$ emissions.

While a $\mathrm{CO}_{2}$ capture unit could be coupled with this technology, this goes beyond the scope of this article, where the effects of biomass and carbon capture and storage are assessed separately. Hereafter, the gasification process based on dry biomass is denoted as B-GSF.

Electricity, natural gas and water are assumed to be available at each node of the supply chain, as the optimal design of their grids is beyond the scope of this work. Limited availability of biomass is considered at each node, as described in Section $5 . \mathrm{H}_{2}, \mathrm{CO}_{2}$ and biomass can be transported between nodes as follows:

- $\mathrm{H}_{2}$ is transported as a gas via truck, train, pipeline and ship.

- $\mathrm{CO}_{2}$ is transported as a liquid via truck, train, pipeline and ship.

- Dry biomass is transported as a solid via truck, whereas no possibility of transport is considered for wet biomass, which must be used where it is available.

Accordingly, we refer to electricity, natural gas and water grids, which are not subject to optimization, while we refer to $\mathrm{H}_{2}$, biomass and $\mathrm{CO}_{2}$ networks, which are designed through the optimization procedure.

\section{Formulation of the optimization problem}

The optimal design of the HSC is tackled by formulating and solving an optimization problem that minimizes the total annual cost and $\mathrm{CO}_{2}$ emissions of the HSC by determining the optimal selection, size and location of the hydrogen production technologies, as well as the optimal structure of the hydrogen, biomass and $\mathrm{CO}_{2}$ networks, to satisfy the hydrogen demand of given end users. Such an optimization problem is formulated as a mixed-integer linear program (MILP), which include both continuous, $x$, and binary variables, $y$, and can be written in general form as

$$
\begin{gathered}
\min _{\boldsymbol{x}, \boldsymbol{y}}\left(\boldsymbol{c}_{1}^{\mathrm{T}} \boldsymbol{x}+\boldsymbol{c}_{2}^{\mathrm{T}} \boldsymbol{y}\right) \\
\boldsymbol{A}_{\mathbf{1}} \boldsymbol{x}=\boldsymbol{b}_{1}, \quad \boldsymbol{A}_{2} \boldsymbol{y}=\boldsymbol{b}_{2} \\
\boldsymbol{x} \geqslant \mathbf{0} \in \mathbb{R}^{X}, \quad \boldsymbol{y} \in\{0,1\}^{Y}
\end{gathered}
$$

where $c_{1}$ and $c_{2}$ represent the cost vectors associated to the continuous and binary decision variables, $\boldsymbol{x}$ and $\boldsymbol{y}$, respectively; $\boldsymbol{A}_{\boldsymbol{1}}$ and $\boldsymbol{A}_{\boldsymbol{2}}$ are the corresponding constraint matrices, with $\boldsymbol{b}_{1}$ and $\boldsymbol{b}_{2}$ being the corresponding constraint known terms; $X$ and $Y$ indicate the dimensions of the vectors $\boldsymbol{x}$ and $\boldsymbol{y}$, respectively. Here, both continuous and binary variables are optimized, with the latter being introduced to model the nonlinearities related to the performance and the capital costs of the considered technologies, as well as to the presence of network connections. The optimization problem is based on mathematical tools presented earlier $[53,54]$, which are here expanded to describe all relevant features of the HSC. All aspects of the optimization problem, namely input data, decision variables, constraints, and objective function are described in detail in Section S1 of the Supporting Information.

The input data to the optimization problem are the (i) hydrogen demand (spatially distributed), (ii) price, carbon intensity and availability of the energy sources, (iii) availability of technology and network options (including the availability of $\mathrm{CO}_{2}$ storage sites), (iv) parameters defining cost and performance of considered production and network technologies, (v) parameters describing the system configuration.

Based on such input data, the optimization problem determines the (i) selection and size of production and network technologies, (ii) input and output streams of production technologies, (iii) flow through network technologies, (iv) amount of feedstocks used for hydrogen production, (v) energy expenditure for transport.

The optimal solution must comply with mass and energy balances, as well as with the models of the production and network technologies.

The optimization algorithm minimizes both the total annual cost and the total annual $\mathrm{CO}_{2}$ emissions. This translates in a multi-objective optimization problem, which can be solved through a variety of techniques. Here, the $\epsilon$-constraint method proposed by Mavrotas is adopted [55].

\section{Analysis summary and general aspects of minimum-cost design}

The study presented in this work is organized in three parts (seeTable 1). Three different supply chains and different system 
Table 1

Summary of the analyses performed to investigate the optimal design of low-carbon hydrogen supply chains.

\begin{tabular}{llll}
\hline & General aspects & Use of biomass \\
\hline Configuration & Ideal & Ideal \\
Energy source & NG & NG, electricity, biomass & no \\
CCS & no & multi-objective & NG, electricity \\
Optimization & minimum cost & minimum emissions \\
Design synthesis & no & & yes \\
\hline
\end{tabular}

configurations are considered in order to (i) investigate general aspects of the minimum-cost design of HSC (Section S2 of the Supporting Information), (ii) determine how to reduce costs and $\mathrm{CO}_{2}$ emissions of HSC by deploying biomass in the context of an idealized system configuration (Section 5), (iii) determine how to reduce costs and $\mathrm{CO}_{2}$ emissions of HSC by deploying CCS in the context of a Swiss case study (Section 6).

First, let us consider the $\mathrm{H}_{2}$ production technologies and the $\mathrm{H}_{2}$ transportation means. Their characteristics, in terms of carbon footprint and costs, are key parameters that, together with the system constraints given by $\mathrm{H}_{2}$ demand, availability of biomass and location of $\mathrm{CO}_{2}$ storage sites, have a major influence on the final structure of the HSC.

While the carbon footprint of different HSC will be discussed in detail in Sections 5 and 6 for a broad range of different scenarios, here we make general considerations concerning the minimum-cost design. We do this by considering the idealized system configuration (see Fig. 1a) and by studying how the optimal system design depends on the effect of scale on plant costs, network losses, degree of demand urbanization, hydrogen transport pressure, minimum hydrogen demand. Whereas the detailed analysis is presented in Section S2 of the Supporting Information, findings highlights the crucial importance of the effect of scale on plant costs and of the network losses (quantified by a loss coefficient measuring the amount of $\mathrm{H}_{2}$ lost per unit distance) in determining whether the hydrogen production facility of a specific supply chain is centralized or decentralized:

- Centralized HSC feature a few, big $\mathrm{H}_{2}$ production plants located close to the nodes of high $\mathrm{H}_{2}$ demand (urban), with $\mathrm{H}_{2}$ being transported to the demand sites.

- Decentralized HSC feature several, small $\mathrm{H}_{2}$ production plants located directly at the demand sites, with no $\mathrm{H}_{2}$ transport.

Concerning the effect of scale on plant costs, there are two typical situations. On the one hand, the cost of plants that are designed and built in a modular way tend to be proportional to the plant size, i.e. the specific capital cost per unit hydrogen produced is more or less constant; in the context of our study this is the case for the PEM electrolyzer. On the other hand, there are plants that incur large fixed costs independent of size; such fixed costs together with variable costs proportional to the scale of the plant determine a dependence of the total capital costs on scale that is much less than linear (e.g. an exponent of about 0.6 in a power law relationship linking scale to costs). Here, this is the case of the SMR and of the gasification technologies, especially when combined with $\mathrm{CO}_{2}$ capture processes. When such different cost structures are taken into account by the system model, technologies of the former type are preferably installed at a small scale in a decentralized context, whereas technologies of the latter type are installed at a large scale mostly in a centralized location.

When the cost of transport technologies is taken into account together with the associated transport footprint (due the hydrogen losses along the transportation routes), a similar trend towards decentralization of hydrogen production is observed when transportation costs and losses are high. The opposite trend, i.e. towards centralized hydrogen production, is observed when such costs and losses are low.

These qualitative considerations are confirmed by quantitative trends (see Section S2 of the Supporting Information) when the HSC model is optimized under different assumptions. The same trends will be observed in the results presented in Sections 5 and 6 below.

\section{Multi-objective optimization of hydrogen supply chains deploying biomass}

Let us now analyze how to reduce the carbon footprint of HSC by powering hydrogen production with energy sources other than natural gas, but without introducing any CCS technology. To this aim, we carry out a multi-objective optimization that minimizes cost and $\mathrm{CO}_{2}$ emissions of HSC where hydrogen can be produced via reforming of natural gas (SMR technology), or using biomass (either reforming of biogas originated from wet biomass, b-SMR, or gasification of dry biomass, BGSF), or through water electrolysis using electricity (PEM electrolyzer, PEME). Note that the last technology represents what is supposed to be the long-term sustainable solution for hydrogen production, assuming the availability of carbon-free electricity.

The HSC serve a demand distributed according to the idealized configuration of Fig. 1-a, which is characterized by urban and rural nodes that are differentiated not only because of the higher demand in the former than in the latter, but also because we assume that biomass is available only in the latter. While NG, electricity and water are available in all nodes in whatever amount needed, biomass availability is limited and its specific amount is characterized by the parameter $\phi$, which is defined as the fraction of hydrogen demand that can be met using biomass. Biomass is assumed to be distributed homogeneously among the rural nodes with equal availability of wet and dry biomass.

For the sake of simplicity, we consider four possible scenarios for the production of hydrogen, namely based on:

(I) Fossil fuels only (SMR using NG), with no renewables available;

(II) Fossil fuels and (possibly low-carbon) electricity (SMR and PEME), but no biomass, i.e. $\phi=0$;

(III) Fossil fuels, electricity and biomass covering $10 \%$ of the $\mathrm{H}_{2}$ demand, i.e. $\phi=0.1$;

(IV) Fossil fuels, electricity and biomass covering up to $100 \%$ of the $\mathrm{H}_{2}$ demand, i.e. $\phi=1$.

The last three cases are representative of all possible levels of availability of biomass. In all scenarios, hydrogen can be transported through pipeline, or using trucks or trains; dry biomass is transported on trucks, whereas wet biomass is not transported and can only be used where available.

\subsection{Cost-emissions Pareto front}

The cost-emissions Pareto fronts for the four different HSC are reported in Fig. 2a, with the shape of the Pareto fronts implying that costs and $\mathrm{CO}_{2}$ emissions cannot be minimized simultaneously. The figure shows that $\mathrm{CO}_{2}$ emissions cannot be reduced by using natural gas only (HSC I). At the same time, $\mathrm{CO}_{2}$ emissions can be reduced only slightly (of about $20 \%$ ) by using electricity through water electrolysis (HSC II). In contrast, deploying biomass allows to further reduce the HSC emissions, the more the higher the biomass availability, $\phi$ (HSC III and IV) is.

In fact, PEME are less carbon intensive than SMR only if consuming electricity is less carbon intensive than consuming natural gas, i.e. 
a)

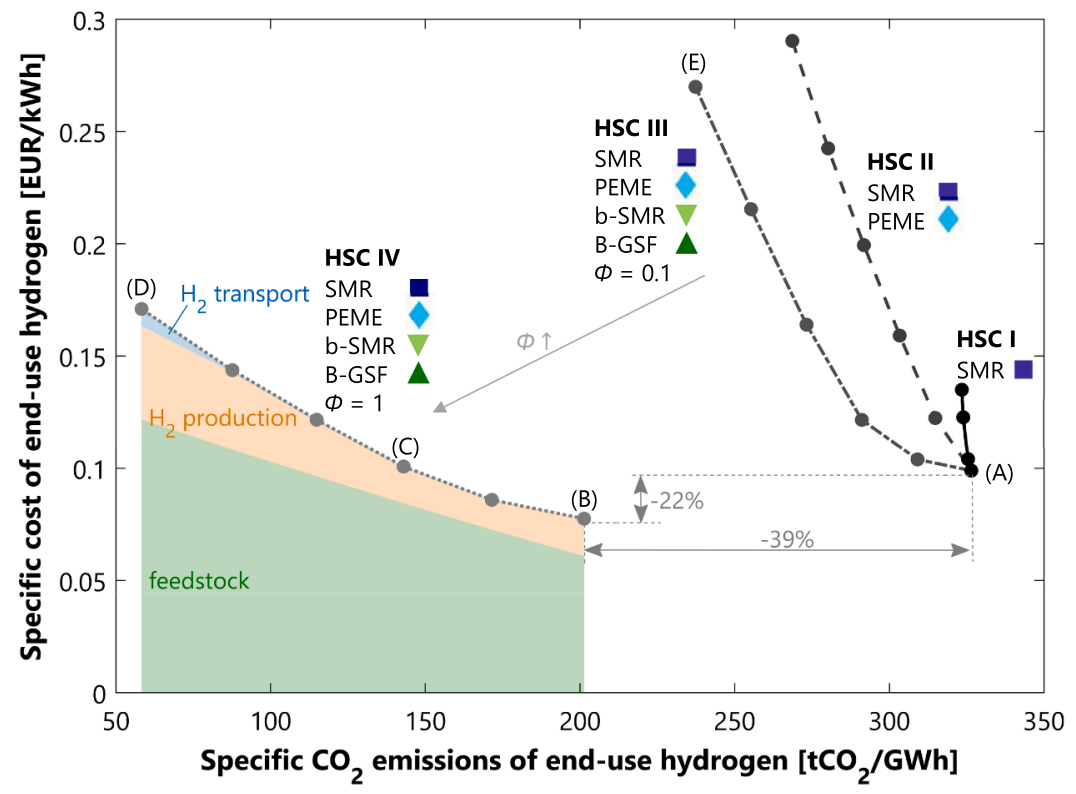

b)
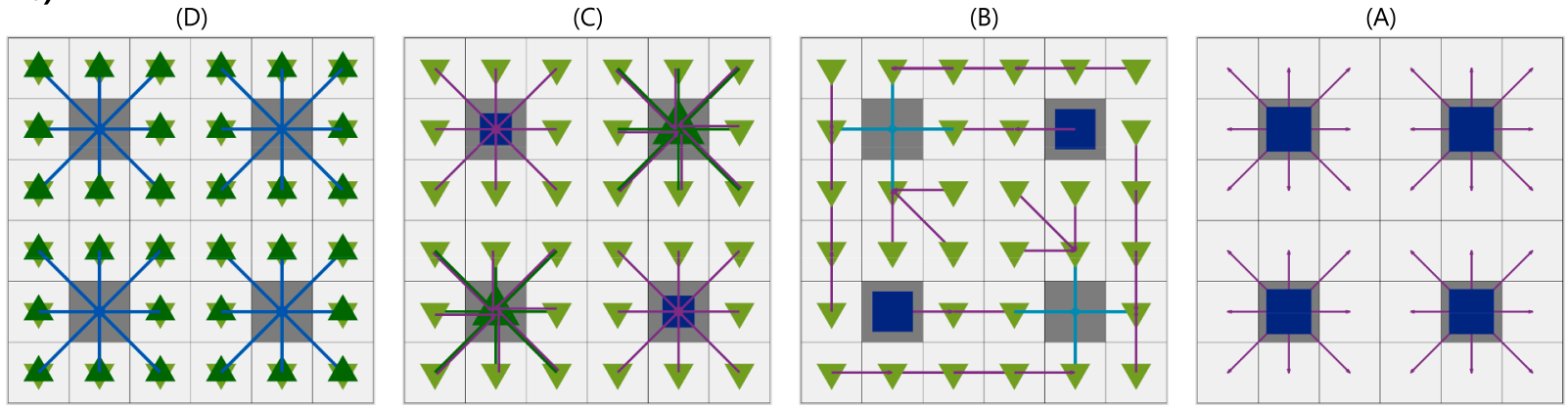

Fig. 2. Multi-objective optimization of the four considered biomass-based HSC: (I) SMR, (II) SMR, PEME (III) SMR, PEME, b-SMR, B-GSF, $\phi=0.1$, (IV) SMR, PEME, bSMR, B-GSF, $\phi=1$. Markers represent performed optimizations. (a) Cost-emissions Pareto front. (b) Representation of optimal HSC structure for four optimizations of interests.

when:

$\frac{\epsilon_{\mathrm{e}}}{\eta_{\text {PEME }}}<\frac{\epsilon_{\mathrm{g}}}{\eta_{\mathrm{SMR}}}$

where $\epsilon_{\mathrm{e}}$ and $\epsilon_{\mathrm{g}}$ are the carbon intensity of the electricity and natural gas grids, respectively; $\eta_{\mathrm{SMR}}$ and $\eta_{\mathrm{PEME}}$ are the conversion efficiencies of SMR and PEM electrolyzers, respectively. The inequality given by Eq. (2) is met in countries in which the electricity mix relies mostly on renewable or nuclear power (e.g. Switzerland, France). In contexts where this is not the case (e.g. Germany, UK, USA), electrolyzers are never installed unless coupled with a dedicated source of low-carbon electricity (e.g. solar or wind). In this work, we consider the average carbon intensity at delivery of the Swiss electricity grid, which is about $127 \mathrm{gCO}_{2} / \mathrm{kWh}$ (see Section S3 of the Supporting Information). This results in the levels of $\mathrm{CO}_{2}$ emissions reported in Fig. 2-a, where electrolyzers have a lower environmental footprint than SMR, but a higher environmental footprint than biomass-based production technologies, which must be thus installed to further reduce the $\mathrm{CO}_{2}$ emissions.

The minimum-cost configuration is the same for supply chains I, II and III (see configuration (A) in Fig. 2-b), whereas it changes above a certain value of biomass availability (see configuration (B) in Fig. 2-b). More specifically, until a certain value of biomass availability centralized hydrogen production via SMR is more cost-effective than distributed hydrogen production via b-SMR. This is due to the high fixed costs of b-SMR and to the corresponding high specific installation costs at small sizes. Above a given value of biomass availability, both costs and $\mathrm{CO}_{2}$ emissions can be reduced with respect to a configuration adopting SMR and PEME only. While the installation cost of both bSMR and B-GSF is higher than that of SMR, the reduction in cost is due to the lower price of wet biomass with respect to natural gas, which offsets the installation cost and results in the $22 \%$ cost reduction going from (A) to (B) in Fig. 2-a. In contrast, the reduction in $\mathrm{CO}_{2}$ emissions is due to the lower carbon intensity of dry biomass with respect to natural gas, electricity and wet biomass, which results in the 39\% emissions reduction going from (A) to (B) in Fig. 2-a. HSC IV, which is fully based on biomass, features a significant reduction in both cost and $\mathrm{CO}_{2}$ emissions with respect to HSC III, which relies on a $10 \%$ biomass availability only.

The breakdown of costs is shown for HSC IV, and similar considerations hold for all supply chains. The larger share of costs comes from the feedstock (green shaded area), which goes from a mix of natural gas and biomass in the minimum-cost optimization to biomass only in the minimum-emissions optimization (see Fig. 2-a). The second most important cost contribution comes from hydrogen production (orange shaded region), whereas hydrogen transport (blue shaded region) contributes to the total costs only when pipelines are installed, due to their large upfront investment.

\subsection{Optimal structure of the hydrogen supply chains}

The structure of the resulting HSC is shown in Fig. 3 in terms of installed capacity (in GW of end-use hydrogen), number of installed $\mathrm{H}_{2}$ production plants and share of network technologies. Note that for each supply chain and each optimization the sum of installed capacities must 

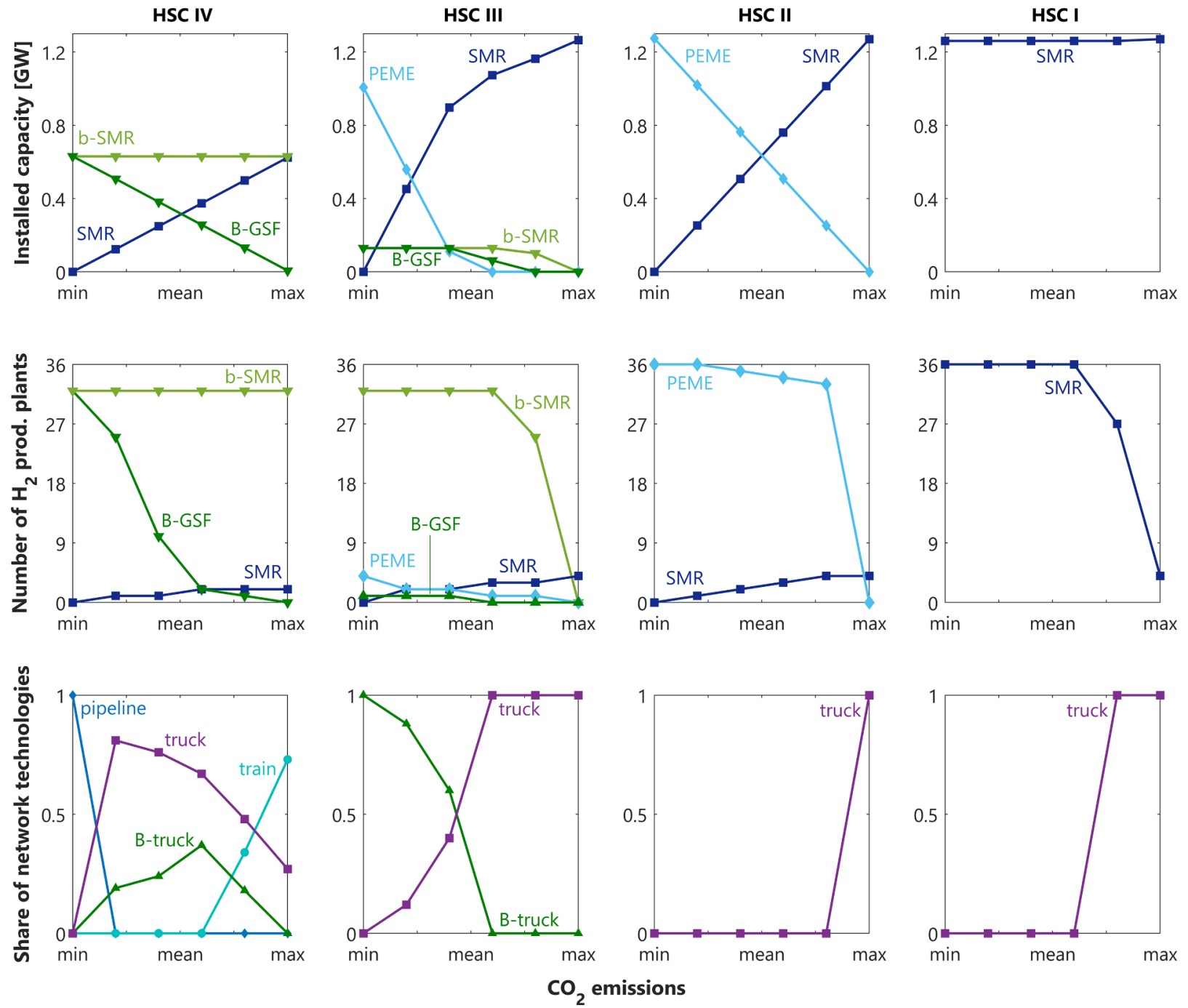

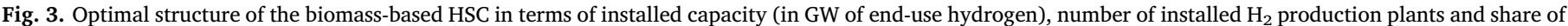
network technologies as function of $\mathrm{CO}_{2}$ emissions.

equal the hydrogen demand. Here, on the horizontal axis we report the dimensionless $\mathrm{CO}_{2}$ emissions, which range from the minimum to the maximum values for all considered supply chains independently of the actual extension of the Pareto front. Configurations of interest are illustrated in Fig. 2-b. The following considerations can be made:

(I) When SMR is the only available technology, $\mathrm{CO}_{2}$ emissions are reduced by going from centralized to decentralized hydrogen production. Indeed, distributed hydrogen production allows avoiding the $\mathrm{CO}_{2}$ emissions related to $\mathrm{H}_{2}$ transport and losses, with the latter causing a larger utilization of primary energy. The minimum-cost configuration is that shown in configuration (A) in Fig. 2-b, which is characterized by hydrogen production within urban nodes, and by hydrogen transport via truck to serve rural end users. A sharp shift towards decentralization is already observed when slightly reducing $\mathrm{CO}_{2}$ emissions $(20 \%$ reduction with respect to the maximum value), with SMR being installed both in urban and rural nodes and hydrogen being transported via truck between rural end users (see the trend of the number of SMR production plants in Fig. 3 - HSC I). Full decentralization, with SMR being installed in all nodes and no network is observed for lower values of $\mathrm{CO}_{2}$ emissions.

(II) Similar considerations hold when adding PEME to the technology portfolio, where an even sharper shift towards decentralization is observed when reducing the $\mathrm{CO}_{2}$ emissions (see the trend of the number of PEME production plants in Fig. 3 - HSC II). While the minimum-cost configuration is the same obtained for HSC I, a fully decentralized structure, with no network, is obtained for a $\mathrm{CO}_{2}$ emissions reduction of $20 \%$ already, where PEME is installed in all rural nodes, and SMR is installed in all urban nodes. SMR gradually disappears and PEME is installed more and more in the urban nodes when decreasing $\mathrm{CO}_{2}$ emissions. The absence of hydrogen network at high values of $\mathrm{CO}_{2}$ emissions depends on the limited impact of size on the cost of PEME, which is then installed in a distributed fashion directly at the location of hydrogen consumption. For equal values of $\mathrm{CO}_{2}$ emissions, such a distributed configuration is more cost competitive than centralized hydrogen production with transport to the end users (see Section 4).

(III) When biomass is available, it is exploited to reduce both costs and $\mathrm{CO}_{2}$ emissions. If the hydrogen demand can be satisfied only partially through biomass ( $10 \%$ here), a progressive deployment of b-SMR (wet biomass) and B-GSF (dry biomass) is observed when reducing the $\mathrm{CO}_{2}$ emissions. More specifically, when going from minimum costs to minimum $\mathrm{CO}_{2}$ emissions, wet biomass is the first energy source being exploited (see configuration (B) in Fig. 2-b and the trend of the number of b-SMR and B-GSF production plants in Fig. 3 - HSC III). This is because its lower operation cost prevails over its higher installation cost with respect to dry biomass. 
Furthermore, while b-SMR is installed in rural nodes (due to the impossibility of transporting wet biomass), B-GSF is installed centrally in urban nodes, with dry biomass being transported there (see configuration (C) in Fig. 2-b). This is because at low values of biomass availability, with a significant electrolysis capacity being installed, centralized hydrogen production is more cost-effective than distributed generation.

Furthermore, when going from minimum cost to minimum $\mathrm{CO}_{2}$ emissions, the transport of biomass increases, while the transport of hydrogen decreases, with the latter disappearing in the minimum-emissions configuration. Both hydrogen and biomass are transported via trucks, whereas hydrogen pipeline is never the network technology of choice along the Pareto front.

(IV) If the entire hydrogen demand can be satisfied through biomass, i.e. $\phi=1$, b-SMR is deployed at the maximum capacity across the entire Pareto front (see configurations (B) to (C) in Fig. 2-b), as it allows reducing both costs and $\mathrm{CO}_{2}$ emissions. B-GSF progressively replaces SMR when reducing $\mathrm{CO}_{2}$ emissions and, contrary to case III, it is also installed directly in the rural nodes (see configuration (D) in Fig. 2-b).

In this case, biomass starts being transported when going from minimum cost to minimum $\mathrm{CO}_{2}$ emissions. However, the biomass transport peaks at a $\mathrm{CO}_{2}$ emissions reduction of $40 \%$. After this, hydrogen transport via trucks peaks at a $\mathrm{CO}_{2}$ emissions reduction of $80 \%$ and is entirely replaced by $\mathrm{H}_{2}$ transport via pipelines in the minimum-emissions configuration.

This analysis shows how the optimal structure of the HSC is affected by whether costs or $\mathrm{CO}_{2}$ emissions are minimized, by the available technology portfolio, and by the value of biomass availability. Further considerations on the interplay between $\mathrm{H}_{2}$ and biomass networks are made in Section S4 of the Supporting Information.

\section{Multi-objective optimization of hydrogen supply chains deploying carbon capture and storage}

Let us now study how CCS technologies coupled with hydrogen production via SMR of natural gas can reduce the associated carbon footprint of HSC, and how this compares with the carbon footprint of hydrogen produced via electrolysis. Here, biomass is assumed to be unavailable for hydrogen production. Note that coupling hydrogen production using biomass and CCS has the potential of yielding negative $\mathrm{CO}_{2}$ emissions, a rather interesting possibility, which is however beyond the scope of this work. Moreover, note that the introduction of CCS implies that the system includes two networks, namely the $\mathrm{H}_{2}$ network already discussed in Section 5 and a $\mathrm{CO}_{2}$ network that connects the $\mathrm{CO}_{2}$ sources (SMR plants) with the $\mathrm{CO}_{2}$ sinks (storage locations); $\mathrm{CO}_{2}$ can be transported using the same vectors as hydrogen.

The HSC serves now a geographically specific demand, namely that corresponding to a case study for Switzerland as illustrated in Fig. 1-b. Note that the network includes two nodes outside of Switzerland. The first is a northern Europe on-shore site (a so-called continental terminal in the Netherlands or in Germany), where hydrogen can be produced and $\mathrm{CO}_{2}$ captured; this serves as a transportation hub for hydrogen and $\mathrm{CO}_{2}$ from or to Switzerland via its connection with a Swiss node, specifically the one located near Basel (located on the river Rhine). The second is a North Sea $\mathrm{CO}_{2}$ storage site, where hydrogen can be produced and $\mathrm{CO}_{2}$ can be captured and/or stored underground.

As to the $\mathrm{CO}_{2}$ capture technology from an SMR-based hydrogen production facility, following the latest authoritative IEAGHG report [50], we consider two possibilities, characterized by different $\mathrm{CO}_{2}$ capture rates, $\psi$ (amount of $\mathrm{CO}_{2}$ captured over total amount of $\mathrm{CO}_{2} \mathrm{co}-$ produced), namely $\psi=0.54$ and $\psi=0.89$, and different unitary costs (see Table S4 in Section S3 of the Supporting Information; these are the IEAGHG "Case 1A" and "Case 2", respectively). We identify the two alternative technologies with the self-explanatory acronyms of SMR-54 and SMR-89. Note that the amount of $\mathrm{CO}_{2}$ captured determines the minimum attainable value of $\mathrm{CO}_{2}$ emissions, as well as the amount of $\mathrm{CO}_{2}$ that has to be transported to the storage site and stored.

Here, we consider four possible scenarios for the production of hydrogen, namely based on:

(I) Fossil fuels only (SMR using NG), with no CCS;

(II) Electricity and fossil fuels (PEME and SMR), but no CCS;

(III) Electricity and fossil fuels without or with $\mathrm{CO}_{2}$ capture (only SMR54) and storage of $\mathrm{CO}_{2}$ in the North Sea;

(IV) Electricity and fossil fuels without or with $\mathrm{CO}_{2}$ capture (SMR-54 and SMR-89) and storage either in the North Sea or in two different locations in Switzerland.

As a matter of fact, the last scenario (HSC IV) consists in turn of three sub-scenarios, the first of which $\left(\mathrm{CO}_{2}\right.$ storage in the North Sea) will be compared to the first three scenarios (HSC I, II, III); then the three sub-scenarios of scenario IV $\left(\mathrm{CO}_{2}\right.$ storage either in the North Sea, or in the Swiss region of Basel, or in the Swiss region of Bern) will be compared among themselves (see 6.3).

\subsection{Cost-emissions Pareto front}

The cost-emissions Pareto fronts for the four different HSC, where $\mathrm{CO}_{2}$ can be stored in the North Sea site only, are shown in Fig. 4-a; similarly to Section 5, the shape of the Pareto fronts implies that costs and $\mathrm{CO}_{2}$ emissions cannot be minimized simultaneously.

The minimum-cost configuration is the same for all supply chains, with SMR only being installed (see configuration (A) in Fig. 4-b). In contrast (and similarly to Section 5), $\mathrm{CO}_{2}$ emissions cannot be reduced by using natural gas only (HSC I), they can be reduced of about $20 \%$ only by using electricity through water electrolysis (HSC II - see Section 5.1), while they can be reduced significantly by deploying CCS technologies. The higher the amount of $\mathrm{CO}_{2}$ captured the lower the environmental impact of the HSC.

Concerning the comparison between SMR coupled with CCS and PEME, the benefit of the former relative to the latter depends on the carbon intensity of the electricity grid. More specifically, using PEME would enable a reduction in $\mathrm{CO}_{2}$ emissions relative to SMR with CCS only if

$\frac{\epsilon_{\mathrm{e}}}{\eta_{\mathrm{PEME}}}<\frac{\epsilon_{\mathrm{g}}-\psi \epsilon_{\mathrm{g}}^{\mathrm{dir}}}{\eta_{\mathrm{SMR}}}$

where $\epsilon_{\mathrm{g}}^{\mathrm{dir}}$ quantifies the direct $\mathrm{CO}_{2}$ emissions resulting from the reforming of natural gas.

To put this into perspective, consider the values used in this work (reported in Section S3 of the Supporting Information), namely $\eta_{\mathrm{PEME}}=0.53, \eta_{\mathrm{SMR}}=0.75, \epsilon_{\mathrm{g}}=237 \mathrm{gCO}_{2} / \mathrm{kWh}, \epsilon_{\mathrm{g}}^{\mathrm{dir}}=197 \mathrm{gCO}_{2} / \mathrm{kWh}$. In this case, Eq. (3) implies that PEME allows reducing $\mathrm{CO}_{2}$ emissions relative to SMR- $\psi$ when $\epsilon_{\mathrm{e}}<94 \mathrm{gCO}_{2} / \mathrm{kWh}$ for SMR-54 ( $\left.\psi=0.54\right)$ and $\epsilon_{\mathrm{e}}<43 \mathrm{gCO}_{2} / \mathrm{kWh}$ for SMR-89 $(\psi=0.89)$. This means that SMR coupled with CCS is the least carbon intensive option in Switzerland (i.e. the case considered here, where $\epsilon_{\mathrm{e}}=127 \mathrm{gCO}_{2} / \mathrm{kWh}$ ), whereas PEME and SMR-54 have a similar environmental impact in France, where $\epsilon_{\mathrm{e}}=92 \mathrm{gCO}_{2} / \mathrm{kWh}[56]$. Note that the average EU28 carbon intensity is about $409 \mathrm{gCO}_{2} / \mathrm{kWh}$ [56], highlighting the necessity of CCS technologies for decarbonizing HSC while waiting for a more spread deployment of renewable energy sources.

Concerning costs, a supply chain relying on PEME only is about twice as expensive as a supply chain adopting $\mathrm{CO}_{2}$ capture for a value of $\mathrm{CO}_{2}$ emissions corresponding to the minimum value attainable with PEME. Here, the plant costs account for about $10 \%$ of the overall cost, while the electricity costs are responsible for the remaining $90 \%$. In Fig. 2a, the breakdown of costs is shown for HSC IV only, and similar considerations hold for all supply chains. The largest share of costs 
a)

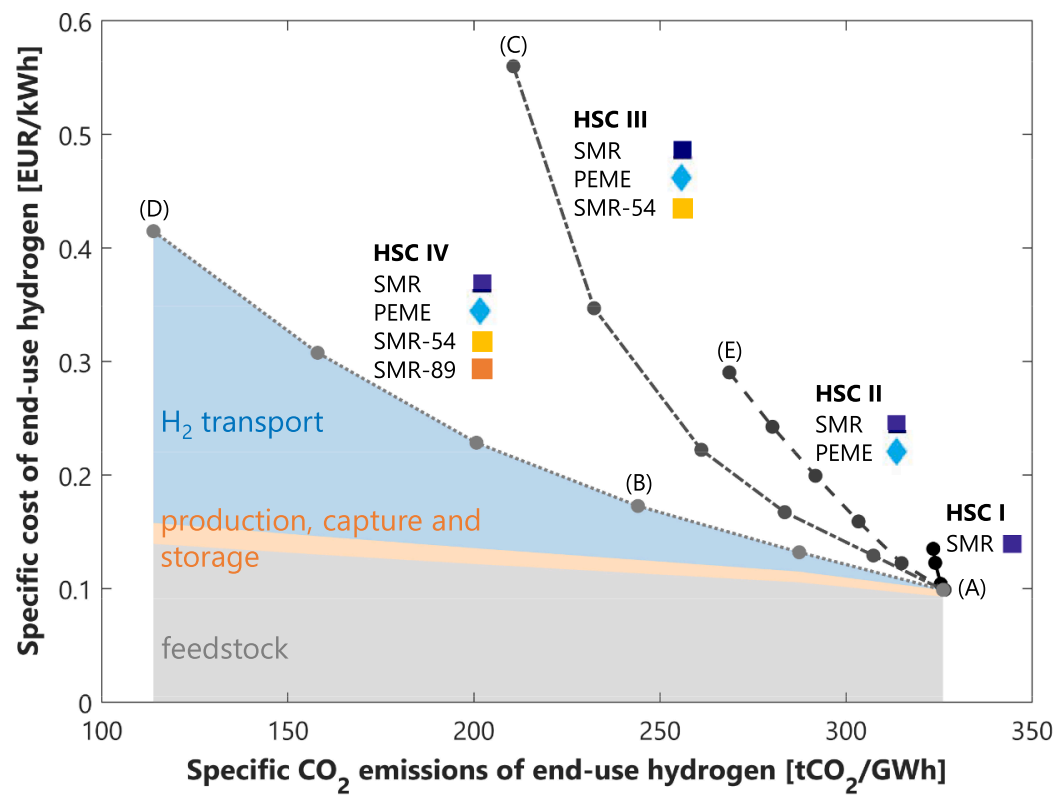

b)

(D)

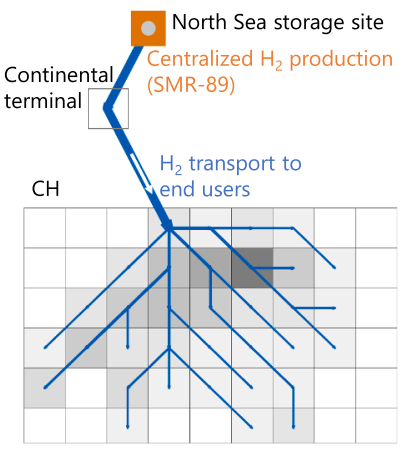

(C)

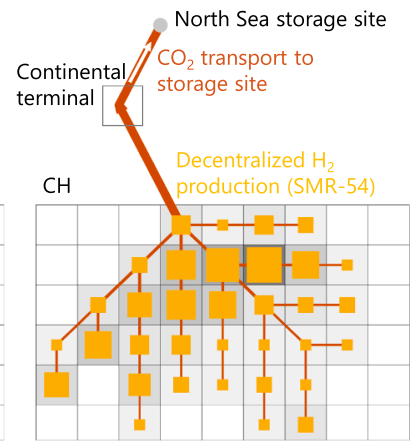

(B)

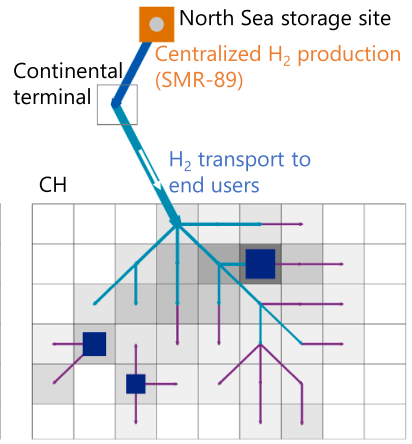

(A)

Fig. 4. Multi-objective optimization of the four considered CCS-based HSC: (I) SMR, (II) SMR, PEME, (III) SMR, PEME and SMR-54, (IV) SMR, PEME, SMR-54 and SMR-89. $\mathrm{CO}_{2}$ storage available only in the North Sea cell (see Fig. 1-b). Markers represent performed optimizations. (a) Cost-emissions Pareto front. (b) Representation of optimal HSC structure for four optimizations of interests. The HSC structure of optimization (E) is reported in Fig. 7. (bottom-right).

comes from the feedstock (gray shaded area) for the minimum-cost optimization and from the $\mathrm{H}_{2}$ transport (blue shaded area) for the minimum-emissions optimization (where CCS is installed). Overall, when CCS is installed, a large cost contribution comes from hydrogen or $\mathrm{CO}_{2}$ transport, whereas the costs of hydrogen production and $\mathrm{CO}_{2}$ storage contribute to a smaller share of the overall value.

\subsection{Optimal structure of the hydrogen supply chains}

The structure of the resulting HSC is shown in Fig. 5 in terms of installed capacity (in GW of end-use hydrogen), number of installed $\mathrm{H}_{2}$ production plants and share of network technologies. Configurations of interest are illustrated in Fig. 4-b. HSC I and II exhibit very similar performances as HSC I and II presented and discussed in Section 5.2, hence here we focus on the deployment of CCS technologies.

The minimum-cost configuration is the same for all supply chains, with SMR only being installed (see configuration (A) in Fig. 4-b), whereas a broader deployment of $\mathrm{CO}_{2}$ capture, as well as higher values of capture rate, are observed when going from minimum cost to minimum $\mathrm{CO}_{2}$ emissions. First, a mix of SMR and SMR coupled with CCS is installed (see configuration (B) in Fig. 4-b); then, only SMR coupled with CCS is installed, where the number and location of $\mathrm{H}_{2}$ production technologies depend on the amount of $\mathrm{CO}_{2}$ captured, hence on the available $\mathrm{CO}_{2}$ capture technology (see configurations (C) and (D) in Fig. 4-b).

More specifically, when only SMR-54 is available (HSC III) the minimum-emission configuration is characterized by decentralized hydrogen production and transport of the captured $\mathrm{CO}_{2}$ to the North Sea storage site (see the number of installed production plants in Fig. 5 and configuration (C) in Fig. 4-b). In contrast, when both SMR-54 and SMR-89 are available (HSC IV), the minimum-emissions configuration is characterized by centralized hydrogen production directly at the storage site with hydrogen being then transported to the end users (see the number of installed production plants in Fig. 5 and configuration (D) in Fig. 4-b).

Independently of the considered supply chain, the minimum-emissions design selects pipeline to transport both $\mathrm{H}_{2}$ and $\mathrm{CO}_{2}$ as this represents the least carbon-intensive network technology. Further considerations on the location and number of available storage sites are performed in the following.

\subsection{Impact of storage location on optimal design}

So far, we have presented the optimal design of HSC considering the possibility of storing $\mathrm{CO}_{2}$ in the North Sea site $\left(\mathrm{CO}_{2}\right.$ storage hub). While today this is the most realistic option for storing the $\mathrm{CO}_{2}$ produced in continental Europe [57], representing a potential game changer for a wide deployment of CCS, we now assess the possibility of having a $\mathrm{CO}_{2}$ 

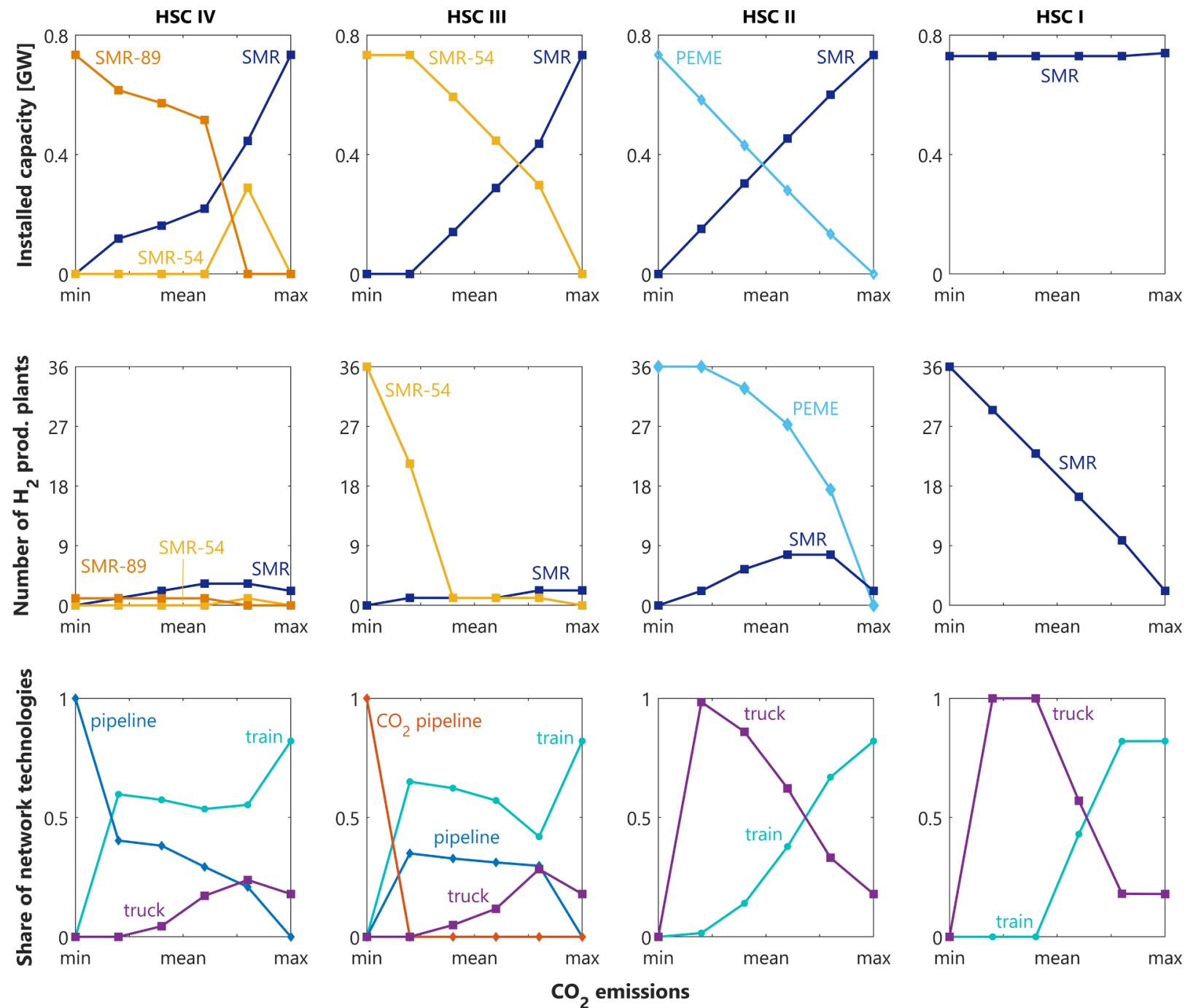

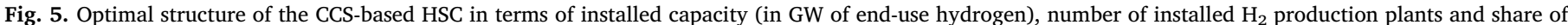
network technologies as function of $\mathrm{CO}_{2}$ emissions.

storage site available in Switzerland.

To this end, we consider three sub-scenarios of HSC IV. All of them include fossil fuels without (SMR) or with $\mathrm{CO}_{2}$ capture (both SMR54 and SMR-89), and electricity (PEME). Each of them features a different location for the $\mathrm{CO}_{2}$ storage, namely the North Sea, the Swiss region of Basel and the Swiss region of Bern (see Fig. 1-b). The resulting cost-emissions Pareto fronts for the three storage locations are shownin Fig. 6. One can note that both lower costs and $\mathrm{CO}_{2}$ emissions of the HSC are obtained when going from the North Sea to Bern, i.e. for a smaller average distance between the storage and the consumption sites. For all storage locations, the minimum-emissions design resembles that of configuration (D) in Fig. 4-b, with hydrogen being produced through SMR-89 directly at the storage site, and being transported through pipeline to all end users. On the one hand, relatively little differences are observed between Bern and Basel, with the former being about $10 \%$ cheaper and $1 \%$ less carbon intensive than the latter. On the other hand, having the storage facility in Switzerland would lead to a cost reduction of about $75 \%$ and a $\mathrm{CO}_{2}$ emissions reduction of about $20 \%$ with respect to the North Sea. The cost reduction is driven by (i) decreased network costs for about $90 \%$, (ii) decreased NG purchase costs for about $10 \%$, (iii) difference in the size of installed production technologies for about $1 \%$. In contrast, the reduction in $\mathrm{CO}_{2}$ emissions is almost entirely driven by the reduction in NG consumption.

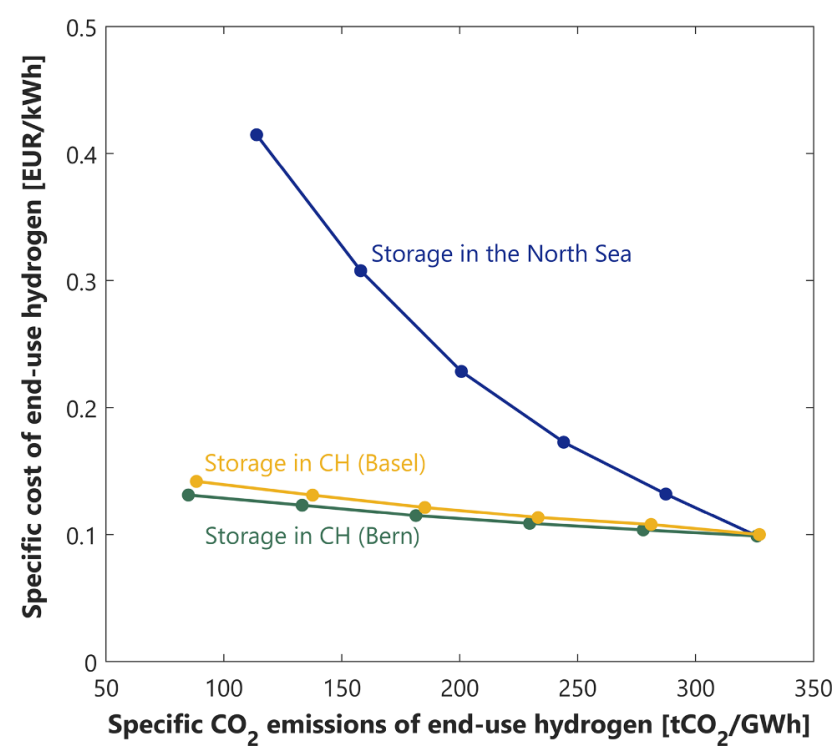

Fig. 6. Impact of storage location on optimal HSC design in terms of cost-emissions Pareto front: North Sea (blue line), Basel (yellow line), bern (green line). Markers represent performed optimizations. (For interpretation of the references to colour in this figure legend, the reader is referred to the web version of this article.) 
Furthermore, let us now consider the case where not only $\mathrm{CO}_{2}$ storage sites are available in Switzerland, but several of them could be exploited at the same time, which includes the limiting case where a $\mathrm{CO}_{2}$ storage site is available at each $\mathrm{H}_{2}$ consumption site. Findings show that a higher number of available storage sites results in smaller transport losses and emissions, hence in lower $\mathrm{CO}_{2}$ emissions, with the minimum value of $\mathrm{CO}_{2}$ emissions being achieved for a configuration with one SMR- $\psi$ unit in each Swiss node and neither $\mathrm{H}_{2}$ nor $\mathrm{CO}_{2}$ transport. On the contrary, the total annual cost is minimized for an intermediate number of available storage sites (equal to four here), which represents the optimal trade-off between production and transport costs. Note that when constrained to one storage site and optimizing for its location, the site resulting in the lowest network distance is selected (see Section 7 for further details).

Here we do not consider limitations on the $\mathrm{CO}_{2}$ storage capacity of the different sites. The reason is twofold. On the one hand, the available storage capacity in the North Sea (e.g. in the Northern Light storage site) is larger than what is currently required and therefore does not represent a limitation $[58,59]$. On the other hand, the available storage capacity in Switzerland has not been assessed, yet, and we aim at assessing the potential implications of storing $\mathrm{CO}_{2}$ there.

In the following section, general considerations on the minimumemissions design of HSC are performed by on the impact of storage location and on the interplay between $\mathrm{H}_{2}$ and $\mathrm{CO}_{2}$ networks.

\section{Analysis of minimum-emissions designs of hydrogen supply chains with CCS}

Let us now focus on the minimum-emissions design of HSC. On the one hand, this is the most relevant design to fulfill the environmental target set by the latest studies $[1,3]$. On the other hand, it allows to not consider the system costs, which complicate the derivation of general design rules. While the competition between $\mathrm{H}_{2}$ and biomass networks is investigated in Section S4 of the Supporting Information, here we focus on HSC deploying CCS.

Within this framework, the impact of the network extension, as well as the competition between hydrogen and $\mathrm{CO}_{2}$ networks, can be studied by introducing the network representative distance, $\Lambda$, which can be defined based on the shortest-path network connection a priori. Let $O$ be the set of nodes of the network, and $i \in O$ be the generic node characterized by hydrogen demand $D_{i}$. Also, let $N_{i}$ be the number of connections defined by the shortest path between the $i$-th hydrogen end user and the $\mathrm{CO}_{2}$ storage facility (e.g. those connections characterizing configurations (C) and (D) in Fig. 4-b). For a given carrier $j$ being transported, such as hydrogen or $\mathrm{CO}_{2}, \Lambda$ is defined as the sum of the distance-weighted flows normalized by the total amount of carrier being produced:

$\Lambda_{j}=\frac{\sum_{i \in O} \sum_{n=1}^{N_{i}} G_{n, j} L_{n}}{\sum_{i \in O} P_{i, j}}$

where $G_{n, j}$ is the flow of carrier $j$ along the $n$-th connection of the shortest path, $L_{n}$ the length of such a connection, and $P_{i, j}$ the amount of carrier $j$ produced in node $i$. Such a representative distance depends on the loss coefficient, $\lambda_{j}$, and on the network extension, $\hat{L}=\sum_{i \in O} \sum_{n=1}^{N_{i}} L_{n}$, only (see Section S5 of the Supporting Information). Both quantities are known a priori, i.e. before running the optimization, with the latter essentially representing the distance between the hydrogen demand sites and the $\mathrm{CO}_{2}$ storage site.

It is worth noting that the costs and $\mathrm{CO}_{2}$ emissions of minimumemissions HSC are found to be a linear function of $\Lambda_{\mathrm{H}_{2}}$ with an increase in $\mathrm{CO}_{2}$ emissions of $0.01 \mathrm{tCO}_{2} / \mathrm{GWh}$ and an increase in cost of 0.13 EUR/MWh per $\mathrm{km}$ increase of hydrogen network representative distance, as illustrated by the Pareto fronts shown in Fig. 6 . Note that $\Lambda$ was not introduced in Section 5 because biomass is treated as a local energy source.

Concerning the competition between hydrogen and $\mathrm{CO}_{2}$ networks, we focus on three limiting cases characterized by (i) centralized hydrogen production and hydrogen transport, as in configuration (D) of Fig. 4-b, (ii) distributed hydrogen production and $\mathrm{CO}_{2}$ transport, as in configuration (C) Fig. 4-b, (iii) distributed hydrogen production through water electrolysis (PEME) and no network installed (given by configuration (E) in Fig. 4-a and Fig. 7). For all cases, we write a simplified expression of the $\mathrm{CO}_{2}$ emissions where the network emissions (i.e. emissions associated to the network installation) are neglected, and a uniform spatial distribution is considered, i.e. $L_{n}=L, \forall n=\left\{1, \ldots, N_{i}\right\}, \forall i \in O$ and $\hat{L}=\sum_{i \in O} N_{i} L$. Furthermore, we consider the same loss coefficient for all carriers, hence $\lambda_{\mathrm{CO}_{2}}=\lambda_{\mathrm{H}_{2}}=\lambda$.

(i) $\mathrm{H}_{2}$ transport. Hydrogen is produced in a centralized plant directly at the $\mathrm{CO}_{2}$ storage site, and is transported to the end users. In this case, the $\mathrm{CO}_{2}$ emissions are due to the baseline NG consumption required to meet the hydrogen demand, to the additional NG consumption required to offset the hydrogen losses, and to the hydrogen transport recompression:

$e_{\mathrm{H}_{2}}=\frac{\epsilon_{\psi}}{\eta^{\mathrm{SMR}}}\left(D+\lambda L \sum_{i \in O} \sum_{n=1}^{N_{i}} G_{n, \mathrm{H}_{2}}\right)+\epsilon_{\mathrm{e}} \zeta \sum_{i \in O} \sum_{n=1}^{N_{i}} G_{n, \mathrm{H}_{2}}$

where $D$ is the total hydrogen demand, $\epsilon_{\psi}=\epsilon_{\mathrm{g}}-\psi \epsilon_{\mathrm{g}}^{\mathrm{dir}}$ is the carbon intensity of natural gas when combined with a $\mathrm{CO}_{2}$ capture technology featuring capture rate $\psi$, and $\zeta$ is the specific energy needed for hydrogen compression (expressed in $\mathrm{kWh}_{\mathrm{e}} / \mathrm{kWh}_{\mathrm{H}_{2}}$ here $10 \%$ pressure loss considered over distance $L$ ).

(ii) $\mathrm{CO}_{2}$ transport. Hydrogen is produced at the demand (and consumption) locations, and $\mathrm{CO}_{2}$ is transported to the storage site. In this case, the $\mathrm{CO}_{2}$ emissions are due almost entirely to the baseline $\mathrm{NG}$ consumption required to meet the hydrogen demand and to the $\mathrm{CO}_{2}$ losses, whereas the emissions due to $\mathrm{CO}_{2}$ transport recompression are negligible:

$$
e_{\mathrm{CO}_{2}}=\frac{D \epsilon_{\psi}}{\eta_{\mathrm{SMR}}}+\lambda L \sum_{i \in O} \sum_{n=1}^{N_{i}} G_{n, \mathrm{CO}_{2}}
$$

(iii) No network. Hydrogen is produced at the demand (and consumption) locations through PEME, and no network is installed as neither hydrogen nor $\mathrm{CO}_{2}$ need to be transported. In this case, the $\mathrm{CO}_{2}$ emissions are purely due to the electricity consumption:

$$
e_{\mathrm{PEME}}=\frac{D \epsilon_{\mathrm{e}}}{\eta_{\mathrm{PEME}}}
$$

By using the definition of the representative network distance given by Eq. (4) within such equations, the following conditions can be derived to identify the optimal minimum-emissions configuration:

- Configuration (i) is optimal, with $\mathrm{H}_{2}$ network being installed, when

$$
\frac{\epsilon_{\mathrm{g}}+\frac{\epsilon_{\mathrm{e}} \eta_{\mathrm{SMR}}}{\lambda L}}{\epsilon_{\mathrm{g}}^{\mathrm{dir}}\left(1+\frac{\Lambda_{\mathrm{CO}}}{\Lambda_{\mathrm{H}_{2}}}\right)}=\psi^{*}(\lambda, \hat{L}) \leqslant \psi
$$

where $\Lambda_{\mathrm{CO}_{2}}$ and $\Lambda_{\mathrm{H}_{2}}$ are the representative distances of the $\mathrm{CO}_{2}$ and $\mathrm{H}_{2}$ networks, respectively. They are completely defined by the loss coefficient, $\lambda$, and by the network extension, $\hat{L}$.

- Configuration (ii) is optimal, with $\mathrm{CO}_{2}$ network being installed, when 


$$
\frac{\epsilon_{\mathrm{g}}-\epsilon_{\mathrm{e}} \frac{\eta_{\mathrm{SMR}}}{\eta_{\mathrm{PEME}}}}{\epsilon_{\mathrm{g}}^{\operatorname{dir}}\left(1-\lambda \Lambda_{\mathrm{CO}_{2}}\right)}=\psi_{*}(\lambda, \hat{L}) \leqslant \psi<\psi^{*}(\lambda, \hat{L})=\frac{\epsilon_{\mathrm{g}}+\frac{\epsilon_{\mathrm{e}} \zeta_{\eta_{\mathrm{SMR}}}}{\lambda L}}{\epsilon_{\mathrm{g}}^{\operatorname{dir}}\left(1+\frac{\Lambda_{\mathrm{CO}_{2}}}{\Lambda_{\mathrm{H}_{2}}}\right)}
$$

- Configuration (iii) is optimal, with no network being installed, when

$$
\psi<\psi_{*}(\lambda, \hat{L})=\frac{\epsilon_{\mathrm{g}}-\epsilon_{\mathrm{e}} \frac{\eta_{\mathrm{SMR}}}{\eta_{\mathrm{PEME}}}}{\epsilon_{\mathrm{g}}^{\mathrm{dir}}\left(1-\lambda \Lambda_{\mathrm{CO}_{2}}\right)}
$$

Eqs. (8)-(10) highlight the key parameters for minimum-emissions design of HSC deploying CCS, which can be grouped into three categories:

- Technology parameters. The conversion efficiency of the production technologies $\left(\eta_{\mathrm{SMR}}\right.$ and $\eta_{\mathrm{PEME}}$ ), the capture rate of the $\mathrm{CO}_{2}$ capture technologies $(\psi)$, and the carbon intensity of the energy grids $\left(\epsilon_{\mathrm{g}}\right.$ and $\epsilon_{\mathrm{e}}$ ) are key to determine the optimal network structure. Here, we focus on the capture rate $\psi$, which defines the amount of $\mathrm{CO}_{2}$ that must be transported and stored.
- Network parameters. The network loss coefficient, $\lambda$, defines $\Lambda_{\mathrm{CO}_{2}}$ and $\Lambda_{\mathrm{H}_{2}}$ and is a key parameter to determine the optimal network structure.

- Overall network extension. The network extension, $\widehat{L}$, defines $\Lambda_{\mathrm{CO}_{2}}$ and $\Lambda_{\mathrm{H}_{2}}$. It essentially defines the distance between the $\mathrm{H}_{2}$ consumption site and the $\mathrm{CO}_{2}$ storage site and is a key parameter to determine the optimal network structure.

Based on this, we identify minimum-emissions design regions, which are function of the loss coefficient $\lambda$, the network extension $\widehat{L}$, and the overall capture ratio $\psi$ (we consider fixed technology efficiencies and emission factors to illustrate the concept). Fig. 7 shows such regions, identified by the threshold surfaces $\psi_{*}(\lambda, \hat{L})$ ( Eq. (8) - red surface) and $\psi^{*}(\lambda, \hat{L})$ (Eq. (9) - blue surface). More specifically:

(i) $\mathrm{H}_{2}$ transport, $\psi^{*} \leqslant \psi$. This region results in centralized hydrogen production at the storage site and hydrogen transport, i.e. structure (D) in Fig. 4-b and Fig. 7. It appears at high values of capture rate only, above around $70 \%$ here, where the amount of $\mathrm{CO}_{2}$ transported results in losses, hence emissions, higher than the emissions due to the amount of natural gas required to compensate the $\mathrm{H}_{2}$ losses. Similarly, the region becomes larger for smaller network,
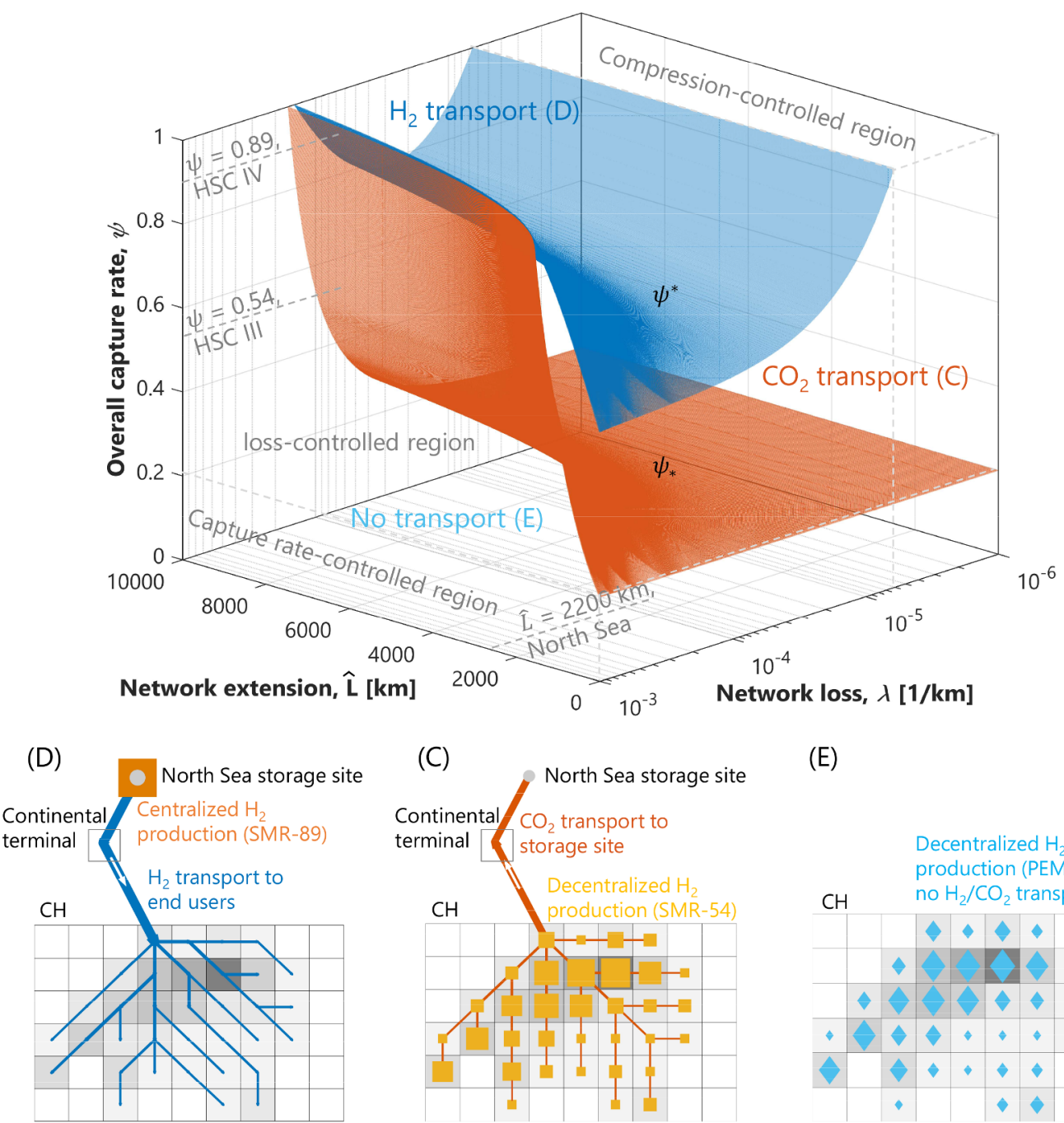

(E)

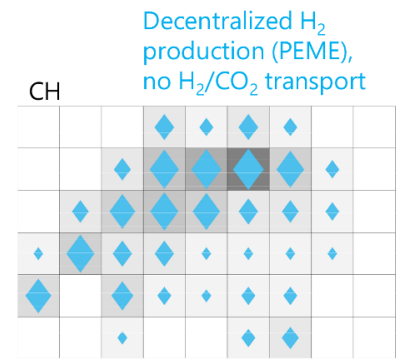

Fig. 7. Threshold surfaces, $\psi_{*}$ (red surface) and $\psi^{*}$ (blue surface), and corresponding minimum-emissions design regions as function of the loss coefficient $\lambda$, the network extension $\widehat{L}$, and the overall capture ratio $\psi$. The three configurations shown are characterized by different values of cost and emissions per unit end-use hydrogen; for the reference conditions considered in Fig. 4-a: (D) $0.41 \mathrm{EUR} / \mathrm{kWh}$ and $114 \mathrm{t}_{\mathrm{CO}_{2}} / \mathrm{GWh}$, (C) $0.56 \mathrm{EUR} / \mathrm{kWh}$ and $211 \mathrm{t}_{\mathrm{CO}_{2}} / \mathrm{GWh}$, (E) $0.29 \mathrm{EUR} / \mathrm{kWh}$ and $269 \mathrm{t}_{\mathrm{CO}_{2}} / \mathrm{GWh}$. (For interpretation of the references to colour in this figure legend, the reader is referred to the web version of this article.) 
where the $\mathrm{CO}_{2}$ losses are predominant over the emissions due to $\mathrm{H}_{2}$ losses (see Section S5 of the Supporting Information). Furthermore, the region disappears for low values of the loss coefficient, below $6 \cdot 10^{-9}$ here, as the energy required for $\mathrm{H}_{2}$ recompression becomes the predominant factor (compression-controlled region). In this case, $\mathrm{CO}_{2}$ transport is favored, and $\mathrm{H}_{2}$ is never transported independently of the values of network extension and capture rate.

(ii) $\mathrm{CO}_{2}$ transport, $\psi_{*} \leqslant \psi<\psi^{*}$. This region results in distributed hydrogen production at the consumption sites and $\mathrm{CO}_{2}$ transport, i.e. structure $(\mathrm{C})$ in Fig. 4-b and Fig. 7. The region appears above reasonable values of capture rate, around $20 \%$ here, where the amount of $\mathrm{CO}_{2}$ captured actually allows the CCS-based HSC to reduce its emissions with respect to an HSC deploying electrolyzers (i.e. structure (E) in Fig. 7-c). At larger values of network extension, $\mathrm{CO}_{2}$ transport replaces $\mathrm{H}_{2}$ transport as the emissions due to hydrogen losses are higher than those related to $\mathrm{CO}_{2}$ losses. Furthermore, the region disappears for a combination of large values of network extension and loss coefficient, where the benefit of transporting either $\mathrm{CO}_{2}$ or $\mathrm{H}_{2}$ would be completely offset by the losses.

(iii) No transport, $\psi<\psi_{*}$. This region results in distributed hydrogen production using electrolyzers, i.e. structure (E) in Fig. 7-c. The region appears at low values of capture rate (capture rate-controlled region), where carbon capture does not allow to reach emissions lower than water electrolysis, and at high values of loss coefficient (loss-controlled region), where the high losses prevent $\mathrm{CO}_{2}$ and $\mathrm{H}_{2}$ transport to be viable options. Similarly, this region becomes larger at high values of the network extension.

Considering the Swiss case study with the possibility of storing $\mathrm{CO}_{2}$ in the North Sea, $\hat{L}=2200 \mathrm{~km} \Lambda_{\mathrm{H}_{2}}=4250 \mathrm{~km}, \Lambda_{\mathrm{CO}_{2}}=2630 \mathrm{~km}$. Taking $\lambda=1.25 \cdot 10^{-7}$, the minimum-emissions design is obtained through configuration (D) for $\psi>\psi^{*}=0.72$ (SMR-89), through configuration (C) for $0.31=\psi_{*}<\psi<\psi^{*}=0.72$ (SMR-54), and through configuration (E) for $\psi<\psi_{*}=0.31$ (PEME). The values of $\psi$ corresponding to the HSC III and HSC IV discussed above are also highlighted.

\section{Summary and concluding remarks}

\subsection{Summary}

This study investigates the optimal design of low-carbon hydrogen supply chains (HSC) aimed at decarbonizing the mobility sector on a national scale. It considers hydrogen production based on several feedstocks and energy sources, namely water with electricity, natural gas and biomass. When using natural gas, the coupling of hydrogen production with carbon capture and storage (CCS) is investigated. The design of the resulting hydrogen, biomass and $\mathrm{CO}_{2}$ infrastructure is performed by solving an optimization problem that determines the optimal selection, size and location of the hydrogen production technologies, as well as the optimal structure of the hydrogen, biomass and $\mathrm{CO}_{2}$ networks. The optimization algorithm is a mixed integer linear program (MILP) that minimizes the total annual cost and the total annual $\mathrm{CO}_{2}$ emissions of the supply chain, while satisfying the hydrogen demand of defined end users. The optimal solution depends on the price and carbon intensity of the energy sources, the hydrogen demand, and the parameters defining cost and performance of the underlying production plants and network options.

The goal of the contribution is to explain the rationale behind the optimal design of low-carbon HSC under different system configurations and to present the case study of Switzerland. We aim at answering questions such as (i) what are the most relevant parameters affecting the optimal design of HSC, (ii) what is the potential of biomass and CCS in reducing the cost and $\mathrm{CO}_{2}$ emissions of HSC, (iii) what is the role of biomass availability in defining the optimal HSC structure, (iv) what is the optimal $\mathrm{CO}_{2}$ capture technology within the framework of low- carbon $\mathrm{HSC}$, (v) what is the impact of the location of the $\mathrm{CO}_{2}$ storage site on the optimal HSC design, (vi) when is convenient to transport biomass, $\mathrm{H}_{2}$ or $\mathrm{CO}_{2}$. To this end, we investigate the competition of several hydrogen production technologies, $\mathrm{CO}_{2}$ capture technologies, and network structures.

First, we investigate general aspects of the minimum-cost design of hydrogen supply chains by referring to an idealized system configuration. Whereas we do not perform a full-blown sensitivity analysis of the optimization model to address the uncertainty of the input data, we believe that this approach allows identifying the most relevant parameters in terms of system design and drawing general considerations independently of any specific application with its specific geographical patterns. Findings highlight the crucial importance of the effect of scale on plant costs and of the network losses in determining whether a supply chain is centralized or decentralized. More specifically, modular technologies (installation costs not affected by the size) are preferably installed at a small scale in a decentralized context, whereas technologies characterized by large fixed costs (strong size dependence) are installed at a large scale mostly in a centralized location. Furthermore, a similar trend towards decentralization of hydrogen production is observed when transportation costs and losses are high. The opposite trend, i.e. towards centralized hydrogen production, is observed when such costs and losses are low.

Next, we determine how to reduce costs and $\mathrm{CO}_{2}$ emissions of HSC by deploying biomass. Indeed, using biomass as energy source allows to reduce both costs and $\mathrm{CO}_{2}$ emissions with respect to HSC based on natural gas (steam methane reforming) and electricity (water electrolysis). Overall, the structure of the resulting HSC strongly depends on whether costs or $\mathrm{CO}_{2}$ emissions are minimized, on the available technology portfolio and on the amount of biomass availability. Concerning the latter, distributed hydrogen production is favored at high values of biomass availability, whereas centralized hydrogen production is favored at low values of biomass availability. Similarly, the competition between $\mathrm{H}_{2}$ and biomass transport depends on the amount of biomass availability.

Finally, we determine how to reduce costs and $\mathrm{CO}_{2}$ emissions of HSC by using CCS. In this case, we consider the Swiss case study, with the possibility of storing $\mathrm{CO}_{2}$ both in Switzerland and in the North Sea. While storing $\mathrm{CO}_{2}$ in Switzerland (i.e. closer to the $\mathrm{H}_{2}$ consumption sites) allows reducing both costs and emissions, the North Sea storage hub is the most realistic option for storing the $\mathrm{CO}_{2}$ produced in continental Europe, and can potentially be a game changer for the deployment of CCS. We observe that the cost, the $\mathrm{CO}_{2}$ emissions and the structure of the resulting HSC are significantly affected by the capture technology (which quantifies the minimum attainable value of $\mathrm{CO}_{2}$ emissions, hence the amount of $\mathrm{CO}_{2}$ that must be stored), the network characteristics and the location of the $\mathrm{CO}_{2}$ storage. More specifically, the optimal network structure is a function of all such aspects, with (i) $\mathrm{H}_{2}$ being produced at the storage site and being transported for small networks, high values of $\mathrm{CO}_{2}$ capture rate and low values of network losses, (ii) $\mathrm{H}_{2}$ being produced at the consumption sites, with $\mathrm{CO}_{2}$ being transported to the storage site for larger networks, lower values of $\mathrm{CO}_{2}$ capture rate and higher values of network losses, (iii) neither $\mathrm{H}_{2}$ nor $\mathrm{CO}_{2}$ being transported, with a fully distributed hydrogen production through water electrolysis being deployed for large networks, low values of $\mathrm{CO}_{2}$ capture rate, and high values of network losses.

\subsection{Concluding remarks}

The optimal design of low-carbon HSC is a complex optimization problem due to the interplay between several production and network alternatives. The main novelty of this paper consists in going beyond the analysis of specific network structures, by understanding the rationale behind the optimal design of low-carbon HSC under different system configurations. General design guidelines, which in some cases can be derived before running an optimization, are determined and 
explained.

While we do not refer to "green" and "blue" hydrogen, the analysis clearly shows how the traditional terminology would need to be revised and must be defined by adopting a system perspective. Hydrogen production via reforming of natural gas coupled with CCS ("blue" hydrogen, or "brown" when based on natural gas only) or biomass, leads to lower $\mathrm{CO}_{2}$ emissions than hydrogen production via water electrolysis ("green" hydrogen) in most countries, due to the high carbon intensity of the electricity mix. Therefore, while we support further deployment of renewable energy sources to decarbonize electricity, we highlight the fundamental role of biomass (when available) and of carbon capture and storage for decarbonizing hydrogen supply chains during such a transition phase.

\section{CRediT authorship contribution statement}

Paolo Gabrielli: Conceptualization, Software, Methodology, Formal analysis, Visualization, Writing - original draft. Flora Charbonnier: Software, Formal analysis. Annalisa Guidolin: Software, Formal analysis. Marco Mazzotti: Supervision, Conceptualization, Methodology, Formal analysis, Visualization, Writing - review \& editing.

\section{Declaration of Competing Interest}

None.

\section{Acknowledgment}

This work was performed within the framework of ACT ELEGANCY, Project No 271498, which has received funding from DETEC (CH), BMWi (DE), RVO (NL), Gassnova (NO), BEIS (UK), Gassco, Equinor and Total, and is cofunded by the European Commission under the Horizon 2020 programme, ACT Grant Agreement No 691712. This project is supported by the pilot and demonstration programme of the Swiss Federal Office of Energy (SFOE). The authors would like to thank the Dipartimento di Energetica of Politecnico di Torino, Italy, and the Civil and Environmental Engineering Department of Imperial College London, UK, for supporting the stays of Annalisa Guidolin and Flora Charbonnier at ETH Zurich during their MSc and MEng projects, respectively. Finally, the authors thank the entire team of the ELEGANCY project, and particularly Cristina Antonini, for the helpful and fruitful discussions.

\section{Appendix A. Supplementary material}

Supplementary data associated with this article can be found, in the online version, at https://doi.org/10.1016/j.apenergy.2020.115245.

\section{References}

[1] IPCC, Global Warming of 1.5 C: Summary for Policymakers; 2018. p 32

[2] UN Environment, Emissions Gap Report; 2018. p 20.

[3] IEA, The Future of Hydrogen; 2019. p. 1-9.

[4] Blanco H, Nijs W, Ruf J, Faaij A. Appl Energy 2018;232:617-39.

[5] Yáñez M, Ortiz A, Brunaud B, Grossmann IE, Ortiz I. Appl Energy 2018;231:777-87.

[6] Lahnaoui A, Wulf C, Heinrichs H, Dalmazzone D. Appl Energy 2018;223:317-28.

[7] Hwangbo S, Lee I-B, Han J. Appl Energy 2017;195:257-67.

[8] Azzaro-Pantel C, editor. Hydrogen supply chains. Elsevier; 2018.

[9] Almansoori A, Shah N. Int J Hydrogen Energy 2009;34:7883-97.

[10] Almansoori A, Shah N. Int J Hydrogen Energy 2012;37:3965-77.
[11] Agnolucci P, McDowall W. Int J Hydrogen Energy 2013;38:5181-91.

[12] Hwangbo S, Lee S, Yoo C. Appl Energy 2017;208:195-209.

[13] Maryam S. Int J Hydrogen Energy 2017;42:24927-38.

[14] Murthy Konda N, Shah N, Brandon NP. Int J Hydrogen Energy 2011;36:4619-35.

[15] Ogumerem GS, Kim C, Kesisoglou I, Diangelakis NA, Pistikopoulos EN. Chem Eng Res Des 2018;131:279-92.

[16] Samsatli S, Samsatli NJ. Appl Energy 2018;220:893-920.

[17] Voldsund M, Jordal K, Anantharaman R. Int J Hydrogen Energy 2016;41:4969-92.

[18] Moreno-Benito M, Agnolucci P, Papageorgiou LG. Comput Chem Eng 2017;102:110-27.

[19] Gabrielli P, Gazzani M, Mazzotti M. Industr Eng Chem Res 2020;59:7033-45.

[20] Yang C, Ogden J. Int J Hydrogen Energy 2007;32:268-86.

[21] Reuß M, Grube T, Robinius M, Preuster P, Wasserscheid P, Stolten D. Appl Energy 2017;200:290-302.

[22] Reuß M, Grube T, Robinius M, Stolten D. Appl Energy 2019;247:438-53.

[23] Guillén-Gosálbez G, Mele FD, Grossmann IE. AIChE J 2009;56:650-67.

[24] De-León Almaraz S, Azzaro-Pantel C, Montastruc L, Pibouleau L, Senties OB. Int J Hydrogen Energy 2013;38:14121-45.

[25] Sabio N, Kostin A, Guillén-Gosálbez G, Jiménez L. Int J Hydrogen Energy 2012:37:5385-405.

[26] De-León Almaraz S, Azzaro-Pantel C, Montastruc L, Boix M. Chem Eng Res Des 2015;104:11-31.

[27] Kim J, Moon I. Int J Hydrogen Energy 2008;33:5887-96.

[28] Sabio N, Gadalla M, Jiménez L, Guillén-Gosálbez G. Comput Aided Chem Eng 2010:121-6.

[29] Kumar RS, Choudhary A, Babu SAKI, Kumar SK, Goswami A, Tiwari MK. Ann Oper Res 2017;250:427-61.

[30] Burkhardt J, Patyk A, Tanguy P, Retzke C. Appl Energy 2016;181:54-64.

[31] Ochoa Bique A, Zondervan E. Chem Eng Res Des 2018;134:90-103.

[32] Wulf C, Kaltschmitt M. Sustainability 2018;10:1699.

[33] Kim J, Lee Y, Moon I. Int J Hydrogen Energy 2008;33:4715-29.

[34] Dayhim M, Jafari MA, Mazurek M. Int J Hydrogen Energy 2014;39:6789-801.

[35] Nunes P, Oliveira F, Hamacher S, Almansoori A. Int J Hydrogen Energy 2015; 40:16408-18.

[36] Balcombe P, Speirs J, Johnson E, Martin J, Brandon N, Hawkes A. Renew Sustain Energy Rev 2018;91:1077-88.

[37] Li L, Manier H, Manier M-A. Renew Sustain Energy Rev 2019;103:342-60.

[38] Cho S, Kim J. Korean J Chem Eng 2016;33:2808-19.

[39] Domínguez-García S, Gutiérrez-Antonio C, De Lira-Flores JA, Ponce-Ortega JM, ElHalwagi MM. Industr Eng Chem Res 2017;56:13812-30.

[40] Bique AO, Nguyen TB, Leonzio G, Galanopoulos C, Zondervan E. Comput Aided Chem Eng 2018:1413-8.

[41] D'Amore F, Sunny N, Iruretagoyena D, Bezzo F, Shah N. Comput Chem Eng 2019;129:106521.

[42] Fuss S, Canadell JG, Peters GP, Tavoni M, Andrew RM. Nat Clim Change 2014; 4: $850-3$.

[43] Minx JC, et al. Environ Res Lett 2018;13:063001.

[44] Yan J. Nat Climate Change 2018;8:560-1.

[45] FSO, Population résidante permanente selon l'âge, par canton, district et commune, 2010-2017; 2018; Available at https://www.bfs.admin.ch/bfs/de/home/statistiken/kataloge-datenbanken/tabellen.assetdetail.5886144.html. Accessed on 2019$11-26$.

[46] FSO, Distribution of road vehicles by vehicle group and canton; 2019; Available at https://www.bfs.admin.ch/bfs/en/home/statistiken/kataloge-datenbanken.assetdetail.je-e-11.03.02.01.01.html. Accessed on 2019-11-26.

[47] Gabrielli P, Gazzani M, Mazzotti M. Appl Energy 2018;221:557-75.

[48] Antonini C, Treyer K, Streb A, van der Spek M, Bauer C, Mazzotti M. Sustain Energy \& Fuels 2020.

[49] Antonini C, Pérez Calvo JF, Mazzotti M; 2020 [in preparation].

[50] IEAGHG, Techno-Economic Evaluation of SMR Based Standalone (Merchant) Hydrogen Plant with CCS; 2017; p 286, Available at https://ieaghg.org/exco_docs/ 2017-02.pdf. Accessed on 2019-11-26.

[51] Cohce M, Rosen M, Dincer I. Int J Hydrogen Energy 2011;36:11388-98.

[52] Sansaniwal S, Pal K, Rosen M, Tyagi S. Renew Sustain Energy Rev 2017;72:363-84.

[53] Gabrielli P, Gazzani M, Martelli E, Mazzotti M. Appl Energy 2018;219:408-24.

[54] Gabrielli P, Fürer F, Mavromatidis G, Mazzotti M. Appl Energy 2019;238:1192-210.

[55] Mavrotas G. Appl Math Comput 2009;213:455-65.

[56] Moro A, Lonza L. Transport Res Part D: Transp Environ 2018;64:5-14.

[57] Sandberg P. Northern Lights project: Developing an open source service for transport and storage of European CO2; 2019; Available at https://www.iva.se/globalassets/info-trycksaker/vagval-for-klimatet/nr-5-per-sandberg-northern-lights-foriva-29-jan-2019.pdf. Accessed on 2019-11-26.

[58] Ringrose P, Greenberg S, Whittaker S, Nazarian B, Oye V. Energy Proc 2017;114:3547-57.

[59] Ringrose PS. Energy Proc 2018;146:166-72. 